Muñoz Salazar, Fernando Vicente. Análisis geográfico de la pobreza en Santa Cruz de Tenerife. GeoGraphos. [En línea]. Alicante: Grupo Interdisciplinario de Estudios Críticos y de América Latina (GIECRYAL) de la Universidad de Alicante, 25 de febrero de 2014, vol. 5, no 65, p. 233-265 [ISSN: 2173-1276]. [DOI: 10.14198/GEOGRA2014.5.65].

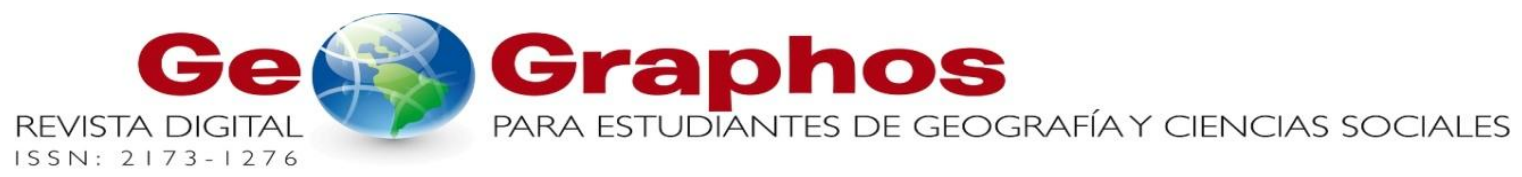

<http://web.ua.es/revista-geographos-giecryal >

Vol. 5. $\mathrm{N}^{\circ} 65$

Año 2014

\title{
ANÁLISIS GEOGRÁFICO DE LA POBREZA EN SANTA CRUZ DE TENERIFE
}

\author{
Fernando Vicente Muñoz Salazar \\ Graduado en Geografía y Ordenación del Territorio \\ Universidad de La Laguna (San Cristóbal de La Laguna, Santa Cruz de Tenerife, Islas \\ Canarias, España). \\ Correo electrónico: Fernandomusal@gmail.com
}

Recibido: 10 de enero de 2014. Devuelto para revisión: 14 de febrero de 2014.

Aceptado: 25 de febrero de 2014

\section{RESUMEN}

La desigualdad designa la falta de equilibrio entre dos o más cosas. El apreciable distanciamiento entre las clases sociales antagónicas está siendo cada vez mayor, construyéndose una jerarquía social cada vez más polarizada que sigue su curso, fruto de un sistema social, económico y territorial que favorece este hecho. Un ejemplo temporal y espacial de este fenómeno sistémico y global lo constituye el municipio de Santa Cruz de Tenerife cuyos indicadores así lo demuestran. Bajo estas circunstancias no es de extrañar que el desempleo, y su corolario, la pobreza y la miseria, se hayan 
acrecentado de una manera evidente, conformando una realidad que indica un reparto desigual de la riqueza o, dicho de otra manera, un reparto injusto del capital y del suelo.

Palabras clave: Desigualdad, trabajo, clases sociales, pobreza.

\title{
GEOGRAPHICAL ANALYSIS OF POVERTY IN SANTA CRUZ DE TENERIFE
}

\begin{abstract}
Inequality refers to the lack of balance between two or more issues. The significant isolation between the different social classes has been increasing and therefore constructed a social hierarchy even more pronounced that keeps on growing. This is a result of a system that favours this. An example of this temporal and spatial isolation is the city of Santa Cruz de Tenerife. If we analyze its signs we confirm this theory. Taking these characteristics into account, it is not surprising that unemployment, and therefore, poverty and misery, have increased in an obvious way, moulding a reality that indicates an unequal distribution of wealth or, in other words, an unfair distribution of capital and land.
\end{abstract}

Key words: Inequality, work, social clases, poverty.

\section{ANÁliSE GEOGRÁFICO DA POBREZA EM SANTA CRUZ DE TENERIFE}

\section{RESUMO}

A desigualdade se refere à falta de equilíbrio entre duas ou mais coisas. A diferença significativa entre as classes sociais antagônicas está cada vez mais, construindo uma hierarquia social cada vez mais polarizado que continua, resultado de um sistema social, económica e territorial que favorece isso. Um exemplo temporal e espacial deste fenômeno global sistêmica é a cidade de Santa Cruz de Tenerife, cujos indicadores provar isso. Nestas circunstâncias, não é de estranhar que o desemprego e seu corolário, a pobreza e a miséria têm aumentado de uma forma óbvia, moldando uma realidade indicando uma distribuição desigual da riqueza, ou, dito de outra forma, a distribuição injusta do capital e da terra.

Palavras chave: Desigualdade, trabalho, clases sociais, pobreza.

\section{ANTECEDENTES}

Mucho se ha dicho y ha escrito sobre la dimensión y definición de la pobreza. Dicho concepto se ha integrado desde hace relativamente poco en el dialecto científico y muchas veces puede resultar algo ambiguo, es por eso que conviene precisar con qué conceptos vamos a trabajar y cómo han ido evolucionando a lo largo de la historia reciente. Es necesario, pues, presentar los antecedentes de nuestro trabajo de investigación. 
Desde el feudalismo hasta el capitalismo la idea de pobreza ha ido variando en su concepción. Mientras que durante el Antiguo Régimen la pobreza se interpreta como un problema moral e individual, con el capitalismo la pobreza comienza a encontrar su explicación y justificación en el desempleo. Y, como argumentaremos a lo largo de este trabajo, resulta curioso como en la actualidad se vuelve a reinterpretar la pobreza como un problema moral e individual, por lo que parece que estamos volviendo a la estigmatización de la pobreza y hacia la consideración del pobre en términos cuasiraciales, como objeto de la caridad particular y estatal.

Pero sin duda, siguiendo a Francisco Torres y Juan Ojeda (Torres Gutiérrez y Ojeda Rivera, 2004), es cierto que a partir del siglo XIX, en función del desarrollo de la revolución industrial en algunos países europeos y, como consecuencia, el desarrollo de las ciencias sociales, se inicia la reflexión científica acerca de la pobreza y la exclusión social. Ya los clásicos marxistas como el propio C. Marx en El Capital (1867) y F. Engels en La situación de la clase obrera en Inglaterra (1845) y en Contribución al problema de la vivienda (1872) describían las lamentables condiciones de vida de la población trabajadora en Londres, en particular, y en el Reino Unido, en general, como país más desarrollado desde el punto de vista del capitalismo. Ambos autores ya ponen de manifiesto la estrecha relación entre pobreza y desempleo.

A finales del siglo XIX comienzan las investigaciones sobre pobreza urbana en EE.UU., al compás del emergente movimiento de reforma social (Du Bois, 1899), y también en Europa (Seebohm Rowntree, 1901). Pero fue en los años veinte y treinta con la llamada Escuela de Chicago (Park, 1926; Ford, 1931), con sus investigaciones sobre las comunidades de inmigrantes y sus áreas de asentamiento, cuando se consolidan estos estudios.

Tal y como apuntan Francisco Torres y Juan Ojeda, desde mediados del siglo XX, los estudios de la pobreza inciden en su carácter estructural ante la estabilización y persistencia de la misma, y ello a pesar de la consolidación del estado de bienestar en algunos países occidentales (Mercier, 1974; Myrdal, 1974; Sen, 1973 y 1976; Towsend, 1979). En esta nueva visión destaca el posicionamiento crítico estructuralista del geógrafo D. Harvey en su obra Urbanismo y desigualdad social (Harvey, 1973) en la que el autor observa la influencia que el capitalismo ejerce sobre la diferenciación social y territorial de la ciudad, en contradicción con el enfoque ecológico que había mantenido la Escuela de Chicago.

Hasta los años setenta del siglo XX, los estudios de este fenómeno social ligaban la pobreza con el desempleo. Es lo que los autores actuales denominan "vieja pobreza" que corresponde al encuadramiento social de grupos diversos como trabajadores no especializados y/o trabajadores manuales, parados, ancianos de clases sociales bajas, minorías étnicas, familias monoparentales y familias numerosas. Pero a partir de los años ochenta aparece el concepto de "nueva pobreza" en los estudios científicos para hablar de los colectivos que constituyen esta subclase urbana (pobres dependientes de ayudas públicas, delincuentes callejeros, los que viven de actividades irregulares, alcohólicos y enfermos mentales...), que al mismo tiempo que tiende a ampliarse en cuanto al número parece adquirir una mayor complejidad. Es así como aparece el término de exclusión social. 
Al referirnos al término pobreza existe disparidad en el uso del mismo en la bibliografía española. Las primeras investigaciones sobre la pobreza (Equipo IMI, 1991, cit. Espluga et al., 2004, p. 75), a principios de los años 90, diferencian exclusión, marginación y precariedad, sin embargo, el término exclusión queda restringido a las situaciones de pobreza absoluta. Posteriormente, a partir de las propuestas de la Unión Europea, el término exclusión se refiere a algo más amplio que la mera pobreza extrema. Actualmente, exclusión social, a causa de su multidimensionalidad sirve para describir situaciones de déficits sociales ya que engloba las causas y los efectos de la pobreza de manera genérica. Para unos se iguala la pobreza con la exclusión social, mientras que otros hacen mayor diferenciación entre exclusión y pobreza tratando de distinguir entre pobreza relativa moderada, que incluye a los individuos inestables socialmente y pobreza absoluta que es el reflejo de la exclusión social propiamente dicha, compuesta por los individuos que carecen de accesos a las necesidades básicas. (Espluga et al., 2004, p. 76).

En resumen, siguiendo a Torres y Ojeda (Torres Gutiérrez y Ojeda Rivera, 2004), desde un criterio meramente cuantitativo, se puede distinguir entre una pobreza relativa, medida por la distribución de la renta, a partir de la cual se suelen definir umbrales para clasificar los distintos niveles de pobreza: 1) precariedad cuando los ingresos medios por persona se sitúan entre el $50 \%$ y el $35 \%$ de los ingresos medios de toda la población en un territorio determinado; 2) pobreza grave la que se sitúa entre el $35 \%$ y el $25 \%$; y 3) pobreza extrema cuando son menores del $25 \%$. Mientras que la pobreza absoluta, se mide respecto a la cobertura de necesidades básicas en un territorio determinado.

Al conjunto de fenómenos relacionados con las desventajas sociales, cuyas diversas combinaciones pueden dar lugar no sólo a situaciones asimilables a la pobreza y la exclusión, sino al riesgo de entrar en dichos estados, se conoce como vulnerabilidad social. Es un concepto que designa una situación intermedia entre la inclusión y la exclusión social.

Por último, la exclusión social es la acumulación de desventajas que impide a las personas ejercer su derecho de ciudadanía plena. Contiene tres dimensiones generales (educación, trabajo y vivienda) y otras específicas (edad, género, salud, etnia).

Por tanto, al margen de lo que subyace en los principales indicadores, la concepción de pobreza es vital para abordar un enfoque científico. Al igual que para C. Marx, para mí, la pobreza es sustancialmente histórica y social, y como consecuencia relativa. Esto es así porque a la pobreza hay que ponerla en relación con el desarrollo de las fuerzas productivas; es decir, con la riqueza general de la sociedad. Por eso no tiene tanto sentido medir la pobreza según algún patrón fijo de bienes materiales, ya que la disponibilidad de los mismos está variando según evoluciona la sociedad. De esta manera, si la pobreza en términos absolutos tiende a descender con el desarrollo capitalista, está aumentando en términos relativos. Esto sin contar que hay largos períodos de crisis y depresiones económicas, como el actual, en el cual la pobreza aumenta en términos absolutos, y numerosas personas son conducidas a la desesperación y el pauperismo más absoluto. (Marx, 1865). 
En cuanto al tratamiento de la cuestión en España, el tema de la pobreza y la exclusión se ha ido convirtiendo en un aspecto muy presente en los estudios de las ciencias sociales en los últimos 25 años. Además, contamos con publicaciones periódicas de gran difusión en el país, como los estudios o informes elaborados por Cáritas, las encuestas del I.N.E. y los informes FOESSA. Desde la Geografía existen múltiples trabajos pioneros que abordan la cuestión, como por ejemplo, el estudio sobre la pobreza y la desigualdad en España de Córdoba Ordóñez y García Alvarado (1991), el de García Ballesteros y Rosa Rivera (1994) y el de Joan Romero y Elisabeth Delios (1997). Por último, en el Departamento de Geografía de la Universidad de la Laguna, las áreas de conocimiento de Geografía Humana y Análisis Geográfico regional también han abordado estos aspectos. Algunos ejemplos de ello los podemos encontrar en las tempranas obras Población, empleo y paro en Canarias (Díaz Rodríguez, M. C., y Martín Ruíz, J. F.) y Análisis geográfico del empleo y paro en Canarias (Díaz Rodríguez, M. C., tesis doctoral). Más recientes son diversas publicaciones y trabajos científicos como: Espacios Degradados y Formas de Exclusión Social en Los Puertos Canarios (Delgado Acosta, C. R., Calero Martín, C. G. y García Herrera, L. M.). Ciudad Oscura, Ciudad Luminosa, Santa Cruz de Tenerife (Díaz Rodríguez, M. C., Delgado Acosta, C. R., Calero Martín, C. G., García Herrera, L. M., Pérez Pérez, M. y Mejías Vera, M. A.), La política social en la iniciativa Urban: los proyectos Urban en Tenerife (Díaz Rodríguez, M. C. y Delgado Acosta, C. R.) o La pobreza en África (Martín Ruiz, J. F.).

\section{OBJETIVOS, HIPÓTESIS Y METODOLOGÍA}

El objeto de esta investigación se fundamenta en el establecimiento de la relación entre mercado laboral y pobreza, cuyos planteamientos teóricos caminan por separado, a través de la aplicación del materialismo histórico. Para ello, desde la disciplina geográfica se ha tratado de argumentar a través de diferentes escalas que van desde lo global a lo local, estableciendo una correlación entre las etapas de crecimiento y decrecimiento económico mundial y la evolución de las bolsas de marginalidad y pobreza en el ámbito municipal de Santa Cruz de Tenerife.

Facilitar la compresión entre esta lógica relación con el problema que se pretende solucionar, la pobreza, ya encierra un objetivo en sí mismo, sin embargo, dar respuesta a la misma razonando las posibles soluciones forman parte del objetivo final y éste se expone y argumenta a lo largo de todo el trabajo.

Los cambios estructurales acaecidos en los últimos años en la sociedad que se asienta sobre el territorio objeto de esta investigación, suponen, no sólo el motivo central de por qué me he interesado y escogido el tema de la pobreza, sino la idea esencial a partir de la cual formular la hipótesis de este estudio.

La manifestación de una serie de hechos, recogidos en prensa y en el vox populi de los ciudadanos de Santa Cruz de Tenerife, refleja en éstos la enorme preocupación que suscitan tales hechos y sus consecuentes cambios. Muchos estudios e investigaciones ya han constatado una serie de consecuencias que confirman esa preocupación: 
El aumento de la pobreza y el distanciamiento entre los que son pobres y los que no es cada vez mucho mayor.

Las condiciones de vida de la gran parte de la población, incluido muchos trabajadores, han sido mermadas en el mejor de los casos y conducidos al límite de la subsistencia en otros.

El conocimiento de dichas constataciones, son el requisito para poder conocer con mayor profundidad cómo se ha generado, qué dimensiones alcanza, cómo se distribuye y qué relaciones tiene con determinados aspectos económicos, sociales y otras escalas, la pobreza en el ámbito territorial estudiado. De tal modo, el resultado de estas conjeturas nos debería permitir obtener unas deducciones más evidentes a partir de las cuales poder aportar soluciones.

El materialismo histórico o concepción materialista de la historia es el método de análisis en el que se basa la ideología del socialismo científico. Es un método científico planteado por Karl Marx en el Siglo XIX, en pleno desarrollo de la Revolución Industrial, cuyas problemáticas, siempre distinguiendo el tiempo histórico, podrían asemejarse a las actuales respecto a la concepción del mundo occidental. La aplicación de este método científico, cuyos mecanismos son reconocidos por gran parte de la comunidad científica, supone para mí, el instrumento que nos posibilita dar respuesta al fenómeno de la pobreza.

El carácter sintético de la geografía, integradora de otras ciencias en el conocimiento del medio social y en su tratamiento del territorio y las trasformaciones de los seres humanos sobre el mismo, hacen que esta disciplina pueda abordar cualquier problema territorial y a cualquier escala.

La "crisis", uno de estos grandes problemas, ha llevado a muchos territorios o partes de éstos a registrar importantes bolsas de miseria y marginalidad.

En este contexto en que nos situamos, el interés por conocer y analizar las diferentes formas que presenta la pobreza en la ciudad de Santa Cruz de Tenerife, se muestra como una empresa lo suficientemente sugestiva, al mismo tiempo que suscita un particular interés; es por ello, que este trabajo tratará de cumplir los objetivos del mismo.

Así pues, el procedimiento seguido se ha basado, principalmente, en recabar toda la información posible acerca de todos los condicionantes y factores endógenos y exógenos que hayan podido incidir de una manera directa en el espacio analizado, la ciudad de Santa Cruz de Tenerife, buscando los paralelismos entre una escala de menor dimensión y la propiamente insular. La información más relevante se ha extraído: a) de la bibliografía dedicada al objeto de estudio y seleccionada posteriormente; b) de la prensa periódica basada en la recopilación de todas las noticias relacionadas con la pobreza en los periódicos más importantes de la prensa isleña en formato digital: El Día y la Opinión de Tenerife, tanto de noticias regionales como insulares y municipales, acompañada de otras noticias de interés de los periódicos regionales y estatales más importantes; c) de los recursos web, relacionados con el tema a tratar; d) de las diferentes entrevistas concedidas por representantes de diversas entidades públicas, 
privadas y alternativas más incidentes en el tratamiento de la pobreza, entre ellas con el Sr. Manuel Sáez, representante del colectivo Baladre, Coordinación contra la Precariedad, el Empobrecimiento y la Exclusión, con la Ilma. Sra. D a Alicia Álvarez González, Concejala de Gobierno del Área de Atención Social y Servicios Personales y con el Sr. Jesús Manuel Gil Agüín, Promotor de Justicia y Fiscal de la Diócesis de Tenerife y profesor de Derecho del ISTIC (Sede de Tenerife), actual párroco de la parroquia de las Mercedes; e) del trabajo de campo realizado in situ sobre algunas de las áreas de la ciudad más vulnerables. Además, a través de los SIGs se ha llevado a cabo el análisis cuantitativo y la representación gráfica y cartográfica, cuyas fuentes oficiales han sido: f) el Observatorio Canario del Empleo y la Formación Profesional (OBECAN); g) el Observatorio Socioeconómico de la Sociedad de Desarrollo de Santa Cruz de Tenerife, portadoras de los indicadores más fiables y representativos obtenidos del Servicio Canario de Empleo y h) el Informe de la Intervención Social de 2012 proporcionado por el Instituto Municipal de Atención Social (IMAS).

Las variables espacio y tiempo, que son las que limitan cualquier acción humana en el territorio, están directamente vinculadas a la geografía y a la historia. Es por este motivo, por su bagaje pedagógico y tradicional y por todo lo anteriormente comentado referido a la situación real que vivimos, que la geografía debe de ser potenciada en la investigación, el tratamiento, el análisis y solución de esta temática.

\section{ALGUNAS RELACIONES ENTRE MERCADO DE TRABAJO Y POBREZA}

La relación entre pobreza y mercado de trabajo es una situación perenne y la articulación entre desempleo y exclusión social un reflejo de ésta; así en Canarias, conforme a los índices presentados en el informe Desarrollo humano y pobreza en España de 2013 por el Instituto Valenciano de Investigaciones Económicas (IVIE), queda al descubierto esta relación. Canarias es con diferencia la Comunidad Autónoma donde los principales indicadores que muestra este informe manifiestan una relación directa entre precariedad laboral y aumento de la pobreza; según el mismo, con un índice de pobreza económica construido con las variables de pobreza material (grado de privación relativa en la capacidad de consumo de las familias) y exclusión social (tasa de paro de larga duración), Canarias ocupa el primer puesto en el ranking de estos indicadores entre el periodo 2006 y 2011, acrecentándose sustancialmente entre el 2008 y 2011.

En el recorrido de toda la historia contemporánea de Santa Cruz el problema de la pobreza ha estado siempre presente, sin embargo, el aumento de esta realidad objetiva en toda la región ha hecho que la pobreza no pase desapercibida y planea en todas las portadas de la prensa, haciendo eco de todas las consecuencias económicas, sociales, educacionales, políticas, sanitarias, etc. Todos estos medios de comunicación manifiestan de forma unánime cómo la pobreza está creciendo de manera preocupante hasta el punto de que podemos encontrar titulares como el siguiente: El aluvión de solicitudes de ayudas en la capital desborda los servicios sociales, aparecido el 3 de marzo de 2013 en La Opinión de Tenerife, edición digital; u otros titulares como: "Los vecinos de Añaza padecen hambruna", también aparecido en La Opinión el 7 de marzo del mismo año. Siguiendo las consecuencias más extremas de la pobreza: el hambre, 
este titular habla por sí sólo: "El hambre azota a los niños canarios", titular del periódico El Día, edición digital del 9 de marzo de 2013.

Pero no sólo en lo social la prensa expresa las consecuencias del aumento de la pobreza; la avalancha de noticias que combina economía y empobrecimiento es muy amplia y también deja reveladores titulares: "La economía sumergida, una válvula de escape a la crisis", del periódico El Día a 3 de marzo; "Canarias pierde 43 empleos al día con la reforma laboral", también del 3 de marzo en La Opinión; o "El 42,63\% de los parados de Canarias no cobra ya prestaciones por desempleo", que aparecía un día más tarde en El Día.

En esta relación de carencias también la educación se ve inmersa, como titular ilustrativo: "Los universitarios canarios lideran las cifras de precariedad", de El Día a 31 de marzo.

Siguiendo esta relación de carencias y aspectos, en la salud también encontramos como los titulares reflejan una vez más la pobreza y sus múltiples dimensiones, con otro significativo ejemplo: "La lista de espera lleva a cientos de canarios a la discapacidad", del 18 de marzo aparecido en El Día.

Titulares como los anteriores, no sólo plasman la multidimensionalidad de la pobreza, sino que ponen de manifiesto las diferencias territoriales respecto al desempleo y a la estructura productiva en el conjunto nacional. Santa Cruz, según los indicadores analizados en este trabajo y la propia prensa de la ciudad, encarna esas diferencias.

Pero, para poder entender los hechos y acontecimientos económicos y sociales que suceden en Santa Cruz de Tenerife, capital de la isla, es preciso señalar su característica dependencia del exterior y su sujeción al sistema dominante cuyas causas y efectos han influido en todas las escalas y a todos los niveles. Si asumimos la sumersión del país, de las islas y de la ciudad en el sistema imperante hemos de reconocer su situación actual, sumido en una profunda crisis "financiera" de orden mundial que está generando estragos en lo social, cultural, económico, político, etc., ante la cual se están imponiendo las soluciones que el movimiento neoconservador propone, separando aún más si cabe la diferencia entre clases y provocando mayor desigualdad. Y todo ello, a pesar de las diferentes reformas del capitalismo que no han logrado solventar su esencia y que por contrario han consolidado sus bases, donde unas pocas personas acaudaladas controlan la propiedad y el capital (terrenos, fábricas, dinero, acciones de la bolsa, bonos, etc.,) en detrimento de la gran mayoría de la población que se ve obligada a vender su fuerza de trabajo a cambio de un salario. Inevitablemente esta premisa mantendrá siempre dos realidades diametralmente opuestas, dos contradicciones que el capitalismo no logrará solventar, la del acaudalado y la del trabajador, la del mundo desarrollado y la del tercer mundo.

\section{EL MARCO TEÓRICO DEL MERCADO DE TRABAJO}

Como hemos ido desarrollando a lo largo del trabajo, el actual sistema imperante, inmerso en una crisis de considerable envergadura, deja secuelas y pone al desempleo 
como principal problema a resolver dentro del marco socio-económico. Para abordar y dar respuesta a esta situación existen muchas teorías que desde la economía y la sociología estudian y explican el mercado de trabajo; pero cabe destacar que son la teoría neoclásica, la institucionalista y la marxista las más reconocidas:

a) Teoría neoclásica.

Según esta teoría, basada en la idea individualista, los fundamentos del análisis del mercado de trabajo no difieren de los análisis de cualquier otro mercado; el trabajador procurará maximizar su utilidad, no se ve afectado por cuestiones sociales, temporales o espaciales. Los individuos se centran básicamente en dos tipos de actividades: trabajo y ocio, imperando siempre el segundo, ya que genera placer, el trabajo por su parte, es considerado únicamente como un medio para obtener un fin necesario: la renta, que facilitará el consumo del ocio. Para los autores neoclásicos, el problema de un trabajador se reduce a optimizar su función de utilidad.

A grandes rasgos, podríamos decir, que el mercado de trabajo en el paradigma neoclásico se basa en la libre competencia y en la ley de la oferta y la demanda, lo cual, supuestamente, ha de dar un equilibrio a los mercados. Para los neoclásicos el cenit se alcanza con la eliminación de las actuaciones de regulación de los gobiernos y sindicatos y la eliminación de todos los impedimentos que puedan alterar la libre competencia en el mercado de trabajo. Para las empresas, sólo los mercados en los que intervienen y las limitaciones tecnológicas pueden suponer un impedimento. Al margen de esto, decidirán cuánta mano de obra contratarán para maximizar los beneficios posibles. Esta situación suele verse inalterada por ambas partes ya que supone la ponderación deseada entre el beneficio del empresario y la utilidad del trabajador, cuya última expresión de los economistas neoclásicos sería la teoría del equilibrio general, inmersa en la teoría del capital humano.

Una de las principales consecuencias de la teoría del capital humano en su explicación viene dada por las diferencias salariales entre trabajadores, ya que las diferencias de cualificaciones conducen, en este marco teórico, a las diferencias de salarios. Así, la aparición del desempleo es debido a que los solicitantes de empleo no aprueban el salario que estipula el mercado (Toharia, 1983, p. 11-18).

b) Teoría institucionalista.

Como respuesta a la escuela neoclásica, para tratar de solventar los problemas de desigualdad que genera ésta, surgen los planteamientos institucionalistas, los cuales no van a ser efectivos. Su concepción del mercado de trabajo tendrá un criterio dual dividiendo a éste en dos grandes segmentos. Para Piore, el mercado primario o superior engloba los puestos de aquellos trabajadores con los salarios mayores, más estables e indefinidos, mientras que, en el mercado secundario o inferior aparecerían los puestos de trabajo más precarios en todas sus variantes. Cierto es, que los teóricos de esta escuela, trataron de fraguar esfuerzos por consolidar un mayor poder sindical y una mayor rigidez del mercado laboral, de igual manera, el sistema de negociación salarial (negociación colectiva) trata de buscar el modo en el que trabajadores y empresarios deciden la renta que se asigna al trabajo. Pero partiendo de la idea base en que se centra esta teoría: "La cuestión es que Piore está suponiendo implícitamente unas relaciones 
sociales de producción muy específicas, en las cuales hay un grupo de personas (empresarios o ingenieros), que tienen poder para contratar o despedir a otro grupo de personas (trabajadores) y que tienen a su cargo el proceso productivo y, por tanto, el proceso de cambio tecnológico, es decir, las relaciones sociales de producción características del capitalismo" (Toharia, 1983, p. 23-28).

Entendemos, por lo argumentado anteriormente, que la aplicación de la teoría marxista, y por eso la desarrollaremos a lo largo del presente trabajo, es la más paradigmática para solventar la problemática de índole laboral, según expone Toharia en su libro, " $E l$ análisis marxista del paro difiere de los dos anteriores en que lo considera como un elemento central del sistema económico capitalista y no como una aberración o un subproducto del mismo" (Toharia, 1983, p. 31). El paro, sin duda, es un elemento siempre presente dentro del sistema capitalista, por tanto, su solución sólo pasa por la abolición de dicho sistema.

\section{c) Teoría marxista.}

El análisis marxista del mercado o proceso de trabajo parte de la diferenciación fundamental entre "fuerza de trabajo, que es la mercancía que se compra y se vende en el mercado, y trabajo, que es el factor de producción que entra en el proceso productivo". Es decir, según esta teoría, no se reconoce que la fuerza de trabajo (trabajo potencial) se convierta de inmediato en trabajo real ya que esto eliminaría el posible conflicto personal entre el trabajador (trabajo potencial) y el empleador (trabajo real) reduciéndose a una mera relación de mercado la de ambas partes, mediada por el salario y correctamente delimitada. Por tanto, una relación de mercado no es sólo una relación entre cosas, sino es además, una relación social entre dos tipos de clases que tienen intereses distintos, y siempre antagónicos, en el proceso productivo (Braverman, 1974, cit. Toharia, p. 19). Por eso, la educación no solamente funciona como un mecanismo de obtención de cualificaciones para los trabajadores, sino que tiene que contribuir en la generación de la conciencia de los trabajadores para conseguir trabajo real a partir de trabajo potencial, distanciando esta concepción del enfoque individualista.

Richard Edwards va un pasito más adelante y trata de analizar la relación social entre estas dos clases: trabajador y empresario. En sus aportaciones plantea "el problema del control" para hacer del trabajo potencial un trabajo efectivo, para los intereses del capitalista, y así, de esta manera, obtener el máximo beneficio posible de la fuerza de trabajo que obtuvo en el mercado, aplicando "un control" para las mínimas oposiciones posibles. Distingue "el control simple": en el que el patrón ejerce su disciplina directamente siendo el más arcaico, y "el control estructural": el control está inserto en la organización misma de la empresa. Dentro del segundo distingue "el control técnico": es la tecnología la que rige el sistema productivo, como por ejemplo las cadenas de montaje y "el control burocrático": los incentivos de la empresa garantizarán que el trabajador no opondrá ningún conflicto. Estos sistemas de control han evolucionado alcanzando unos grados de sofisticación elevados, no obstante, podemos observar su coexistencia en el sistema imperante en todas sus variantes (Edwards, 1974, cit. Toharia, p. 20). 


\section{EL MARCO HISTÓRICO DE LOS MODELOS TEÓRICOS DEL MERCADO DE TRABAJO}

El paso del capitalismo de la libre concurrencia al imperialismo a finales del siglo XIX supuso para las ciencias sociales, en general, y para la economía política, en particular, el abandono de sus inicios materialistas y su paso al bando de la reacción. La burguesía, de clase revolucionaria había pasado, al tomar el poder político, a ser la nueva clase antagónica con el proletariado. Las nuevas ciencias sociales, en su lucha con el materialismo histórico, hizo desaparecer de la academia a la economía política, generando ahora la denominada economía neoclásica. Ésta ofreció un nuevo paradigma que aprovechó la parte idealista de la economía política ricardiana para aportar la teoría marginalista en la explicación del funcionamiento del capitalismo. Se retocaba la teoría del valor, la producción y la distribución. La consecuencia inmediata de este nuevo paradigma del valor es que la teoría de la distribución se convierte en un problema de determinación de los precios de los servicios de los factores productivos, que reciben ingresos como propietarios individuales o grupos sociales mínimos (familias y empresas), más que un problema de reparto del excedente entre las clases sociales, que ahora desaparecen del análisis; lo mismo ocurre con la producción, donde se eliminan las relaciones sociales entre clases, sustituyéndola por la de coste alternativo o de oportunidad.

El paradigma marxista fue el primero de todos desde el punto de vista histórico. En la tradición marxista el salario real es exógeno al sistema, y está determinado por el nivel de subsistencia o convencional. Este salario de subsistencia no sólo incluye los requerimientos de alimentación que permitan la subsistencia del trabajador y su familia, sino también incluye el logro de ciertos estándares de vida, los que se determinan por las convenciones sociales, el cambio tecnológico y el conflicto social o lucha de clases. Marx enfatizó este último elemento en la determinación del salario real, aunque también habló del papel de la competencia.

En el resumen de cada teoría sobre el mercado de trabajo hemos seguido a A. Solimano (Solimano, 1988) en la primera y segunda etapa del imperialismo (inicio y desarrollo del imperialismo), mientras que para la tercera o actual (crisis del imperialismo) hemos resumido a E. de la Garza (de la Garza Toledo, 2010), pero encuadrando temporalmente cada una de ellas dentro de las etapas del imperialismo, tal como lo definió el marxismo clásico, con el objetivo de comprender históricamente el proceso de las ideas en torno al mercado laboral y sus disfunciones, como la creación de pobreza sistémica por parte del capitalismo. Así tenemos que en cada una de las etapas del imperialismo -primera o inicio, segunda o desarrollo y tercera o crisis, como fase superior del capitalismo, la explicación del funcionamiento del mercado laboral y la pobreza por parte de la ciencia establecida fue diferente:

1. En la primera etapa del imperialismo (1871-1945).

Surge y se aplica el enfoque o paradigma neoclásico del mercado de trabajo o, como señalan algunos autores, prekeynesiano (Pigou, 1929; Clay, 1933). Señala el pleno empleo como estado normal de funcionamiento de la economía. El nivel de empleo se determina por la igualdad entre demanda y oferta de trabajo; se excluye la posibilidad de desempleo involuntario en la economía. La política económica está orientada a 
perfeccionar el funcionamiento del mercado laboral, eliminando los factores que interceden en el mecanismo de salarios reales (impuestos a la mano de obra, leyes de inamovilidad, subsidios de desempleo, etc.). Fracasa con el Crac de 1929.

2. En la segunda etapa del imperialismo (1945-1980).

Aunque ya se elabora en los años treinta, surge y se aplica principalmente el paradigma keynesiano (Keynes 1936), siendo reexaminado en los años sesenta y setenta. Señala que el desempleo en el capitalismo es en gran medida de carácter involuntario, lo que imposibilita que los trabajadores encuentren trabajo al salario real vigente. El desequilibrio en el mercado de trabajo se vincula a otros desequilibrios, en particular en el mercado de bienes. No existen fuerzas en el sistema económico que corrijan los desequilibrios en el desempleo y de ahí el papel que puede jugar el Estado. Fracasa con la crisis de 1973.

Al mismo tiempo se reelabora antiguas teorías, intentando acomodarlas a los nuevos tiempos (teoría neoclásica), desvirtuándolas (neomarxistas) o creando propuestas eclécticas (institucionalismo o enfoque de los mercados segmentados).

La vieja teoría neoclásica (Phelp, 1970; Friedman, 1968; Lucas, 1973; Rapping, 1969), que va a retener los supuestos de equilibrio en el mercado de trabajo, enfatizando en el rol de la incertidumbre y la información imperfecta en la generación de fluctuaciones del empleo durante el ciclo económico. No podían sostener la tesis neoclásica de principios de siglo $\mathrm{XX}$.

El enfoque neomarxista (Sweezy, 1942, Morishima, 1973; Marglin, 1984), que reinterpreta las tesis de Marx sobre la ley de población bajo el capitalismo, recogiendo únicamente un aspecto de la naturaleza del salario real, el aspecto endógeno, dejando de lado el exógeno que para Marx era el principal para comprender la naturaleza del capitalismo.

El paradigma de los mercados segmentados tiene su origen en los institucionalistas norteamericanos (Dunlop, 1938; Kerr, 1950), seguidos por dualistas (Doeringer y Piore, 1971) y versiones latinoamericanas (Souza y Tokman, 1986). Señalan que el mercado de trabajo es mejor descrito como segmento que como agregado homogéneo. Así encontramos el segmento formal o primario o central o protegido y el informal o secundario o periférico o no protegido. Los mecanismos en ambos segmentos para explicar el salario difieren. La segmentación tiende a ser permanente. Se presenta como un híbrido entre la teoría neoclásica (salarios reales flexibles) y la neomarxista (modos de producción modernos y atrasados).

3. En la tercera etapa del imperialismo (1980 a la actualidad).

En la tercera etapa se abandonan los postulados keynesianos y se vuelve a retomar el paradigma de la economía neoclásica. Es lo que se conoce como restructuración productiva y de los mercados laborales iniciada en los años ochenta. Conjuntamente y/o como crítica a la relaboración de la teoría neoclásica aparecen los incipientes paradigmas postmodernos. Aparecen nuevas áreas de interés como los "trabajos no clásicos tradicionales" y los trabajos "modernos" y nuevos conceptos y debates en torno 
al "fin del trabajo" y la "fragmentación de las identidades". Esta nueva sociología del trabajo trata de acercarse a las teorías sociales postmodernas actuales y problematizar la tesis de la fragmentación de las identidades y, por tanto, del fin de los sujetos colectivos que parten del trabajo.

Desde el punto de vista de la restructuración productiva aparecen numerosas teorías como la del nuevo institucionalismo, la de los neoschumpeterianos, la de la especialización flexible, la del "industrial governance", cadenas globales, aprendizaje tecnológico, que debaten con la teoría económica neoclásica y que también analizan el mercado de trabajo.

Según Enrique de la Garza Toledo (2010), hubo tres rivales a batir en esta nueva sociología del trabajo, denominada Nuevos Estudios Laborales: a) las antiguas historias del movimiento obrero que se basaban en la toma de conciencia y de la ideología de sus dirigentes; este debate se ganó con los estudios de las condiciones de trabajo (no reducidas al salario) y de vida de los trabajadores, lo que supone una crítica a la tesis de los clásicos marxistas; b) el dependentismo con su teoría centro-periferia; y c) la economía neoclásica que salió fortalecida con la instauración de los modelos liberales, con su instrumental matemático y sus conclusiones categóricas a favor de la flexibilización. Continúa de la Garza diciendo que el más difícil de batir fue el tercero, ya que estos Nuevos Estudios Laborales aparecen las más de las veces como estudios de caso, a lo sumo encuestas poco representativas y, sobre todo, porque ponen el acento en la necesidad de una nueva institucionalidad no reducida al simple mercado sino derivada de los acuerdos entre actores.

Se concluye en esta tercera etapa o de crisis definitiva del imperialismo la ausencia de teoría (la poca que quedaba venía del marxismo y esta fue sometida a crítica y definitivamente abandonada) y el empirismo de las nuevas teorías sobre el mercado laboral no han podido hacer frente a la implantación de los modelos neoliberales. Paradigma neoliberal que ahora se adocena con las teorías posmodernas. Por ejemplo, siguiendo a Enrique de la Garza, se reconoce que el mercado no puede hacerlo todo con la aplicación de la flexibilización laboral. Estos autores se erigen entonces en reformadores del neoliberalismo, es decir, no se trata de cambiar la esencia de éste, sino de diseñar "instituciones parche", que mitiguen los choques de flexibilidad entre los menos aptos en cualificaciones y psicológicamente para esta gran transformación. Entre las "instituciones parche" que proponen, unas aparecen inofensivas y de escasa efectividad, como que los sindicatos cambien de función a una suerte de agentes de colocación de sus agremiados que queden desempleados, o de fomentar el espíritu de que no todo trabajo debe ser mercantil. Otras son contradictorias con sus propios supuestos, como proponer "categorías zombi" propias del Estado benefactor, como asegurar a toda la población un salario básico mínimo o bien la "flexiseguridad" (fondos estatales para los que temporalmente queden desempleados por la flexibilización). Es decir, una mezcla de diferentes paradigmas que conduce, por un lado, a la miseria de la teoría sobre el mercado laboral y, por otro, a la continuación y acentuación de la miseria de la población trabajadora. 


\section{EL EJÉRCITO INDUSTRIAL DE RESERVA Y EL MERCADO LABORAL}

Fuese cual fuese su forma, ya fuese como dinero, como mercancías o como medios de producción, el capital es trabajo. Trabajo que ha sido realizado en el pasado como fruto del ciclo de producción y que se convierte en capital cuando el capitalista se apropia de su uso en la acumulación de más capital. Al mismo tiempo, el trabajo es comprado por el capitalista para activar el proceso de producción, es decir, el capital. De esta forma, trabajo y capital son tan complementarios como polos opuestos en la sociedad capitalista. Así, comienza el funcionamiento de cada empresa y en todas las escalas, siendo esta dualidad de enormes dimensiones la que domina la estructura social. La parte del capital que en cada proceso de producción se convierte en fuerza de trabajo viva, es la parte del capital de la cual subsiste la población trabajadora y la representa. Por este motivo, los trabajadores son aquellos que ponen a rodar los procesos de producción por los cuales se obtiene el capital, y como responsables de los mismos, legítimos acreedores de la plusvalía que éste genera. Así, sus modos de trabajo, su estructura ocupacional y la distribución en sus empresas o puestos de trabajo vienen determinados por los procesos de acumulación del capital en circulación, pudiendo ser atrapada, liberada o lanzada a determinados lugares de la estructura social, en cuyo último escalafón se encuentra la pobreza. (Braverman, 1974, cit. Toharia, p. 321-322).

Esta ha sido una aproximación al entendimiento del papel de las clases trabajadoras, cuyos atributos fundamentales permanecen estáticos en el tiempo, y también se refleja en las sociedades modernas, de las cuales España y sus territorios insulares forman parte.

El análisis y diagnóstico de las consecuencias del capitalismo es planteado por primera vez por el propio Marx, no es nueva esta situación. En lo relativo al crecimiento y extensión de la pobreza, el pauperismo y marginalidad son la última consecuencia de la precarización laboral. Marx en el capítulo XXIII de su obra El Capital titulado "La ley general de la acumulación capitalista", divide a la población trabajadora en dos: El ejército obrero activo o población trabajadora siempre empleada y el ejército industrial de reserva o sobrepoblación relativa. Perteneciente a este segundo subtipo encontramos a todo aquel trabajador empleado a medias o desempleado y contiene constantemente 3 formas: sobrepoblación fluctuante (mano de obra eventual), sobrepoblación latente (población agrícola) y sobrepoblación estancada (empleo irregular). Y por último, el pauperismo o asilo de inválidos del ejército activo, dentro del cual encontramos, en orden de exclusión, a: 1) personas aptas para el trabajo, 2) los huérfanos e hijos de pobres, 3) personas degradadas, envilecidas, no aptas para el trabajo (mutilados, enfermos, viudas) y 4) el proletariado en harapos o lumpenproletariado (vagabundos, delincuentes y prostitutas).

Según la ley general absoluta de la acumulación capitalista, correspondiente al capítulo XXIII de "El Capital", cuanto mayor es la riqueza social, el capital en funcionamiento, la dimensión y la energía de su aumento, y, por lo tanto, también la magnitud absoluta del proletariado y la fuerza productiva de su trabajo, mayor será también el ejército industrial de reserva. Pero, por el contrario, cuanto mayor es ese ejército de reserva respecto del ejército obrero activo, más masiva es la sobrepoblación consolidada, cuya miseria se encuentra en razón inversa de su martirio en el trabajo. Cuanto mayor es el ejército de reserva industrial, mayor es el pauperismo oficial. 
Esta ley determina una acumulación de miseria correspondiente a la acumulación de capital. La acumulación de riqueza en un polo es, pues, al mismo tiempo, acumulación de miseria, tormento de trabajo, esclavitud, ignorancia, brutalización y degradación moral en el contrapolo, esto es, del lado de la clase que produce su propio producto como capital. "De ahí la insensatez de la sabiduría económica que predica a los trabajadores que adapten su número a las necesidades de valorización del capital". (Marx, 1867).

Esta ley ha sido perfectamente apreciable en Santa Cruz de Tenerife, en un primer momento y coincidiendo con "La Gran Depresión del 29", primera gran crisis del capitalismo cuya respuesta sería el keynesianismo, se recurrió al ejército industrial de reserva o sobrepoblación relativa en su forma latente: emigración del campo a la ciudad de los campesinos pobres de las Islas (1945-1973). Para la segunda gran crisis capitalista: "Crisis del petróleo de los 70" cuya respuesta fue el neoliberalismo, en Santa Cruz se recurrió en un primer momento (1973-1998) al ejército industrial de reserva o sobrepoblación relativa en su forma estancada (barrios populares de la ciudad) y latente (campesinos pobres de la España rural: Andalucía y Galicia), y, en un segundo momento (1998-2008), además de los anteriores, se suma la sobrepoblación relativa latente extranjera (campesinos pobres de África, América Latina y Este de Europa). Llegados a la tercera gran crisis: "Crisis financiera actual", la pregunta que surge es: ¿Qué solución aplicará el capitalismo santacrucero en un momento de crisis que puede durar décadas, y que está llenando de sobrepoblación relativa estancada los barrios populares de la ciudad (familias de los antiguos campesinos isleños y trabajadores peninsulares, africanos, latinoamericanos y europeos del Este)? quienes, ante la falta de trabajo, van cayendo rápidamente en el pauperismo.

\section{SANTA CRUZ DE TENERIFE: MARCO GEOGRÁFICO, ANÁLISIS CUANTITATIVO Y ESPACIALIZACIÓN DE LA POBREZA}

La capital de la isla de Tenerife, Santa Cruz de Tenerife, se sitúa en el noreste de la misma, presentando dos grandes áreas con características topográficas bien diferenciadas. Por un lado, encontramos la rampa lávica que parte desde la altiplanicie de La Laguna, formando una serie de escalones de mayor o menor pendiente, que desciende hasta el mar, lugar donde se asienta la mayor parte de la ciudad construida. Por el otro, encontramos el macizo de Anaga, con un relieve muy erosionado a causa de su mayor antigüedad, debido a lo cual comprende numerosos barrancos, crestas, roques, degolladas, montañas, etc., como resultado de un proceso de modelado importante y continuado a lo largo del tiempo desde su génesis en el periodo Mioceno.

De igual manera, la costa del municipio contiene dos ámbitos bien diferenciados. Por un lado, encontramos la costa propia de la ciudad, caracterizada por la inexistencia de un litoral muy accidentado, con playas encajadas en la desembocadura de algunos barrancos y muy cercanas a núcleos poblacionales. El litoral costero de este ámbito se encuentra ocupado en gran medida por el puerto de la ciudad. Por el otro, encontramos las costas del Macizo de Anaga, más accidentadas, caracterizadas por presentar un perfil estructural, ser altas y rocosas. Sus principales playas se localizan en zonas abrigadas y, es en sus inmediaciones, donde único se concentra la escasa población que habita en la costa. (GEVIC, 2013). 
El análisis cuantitativo se ha realizado a partir de los datos proporcionados por el Observatorio Socioeconómico de la Sociedad de Desarrollo de Santa Cruz de Tenerife, mediante la representación gráfica y cartográfica.

Para representar las diferentes áreas del municipio la delimitación utilizada ha sido por códigos postales:

\section{Figura 1. Áreas del municipio de Santa Cruz de Tenerife por Códigos \\ Postales}

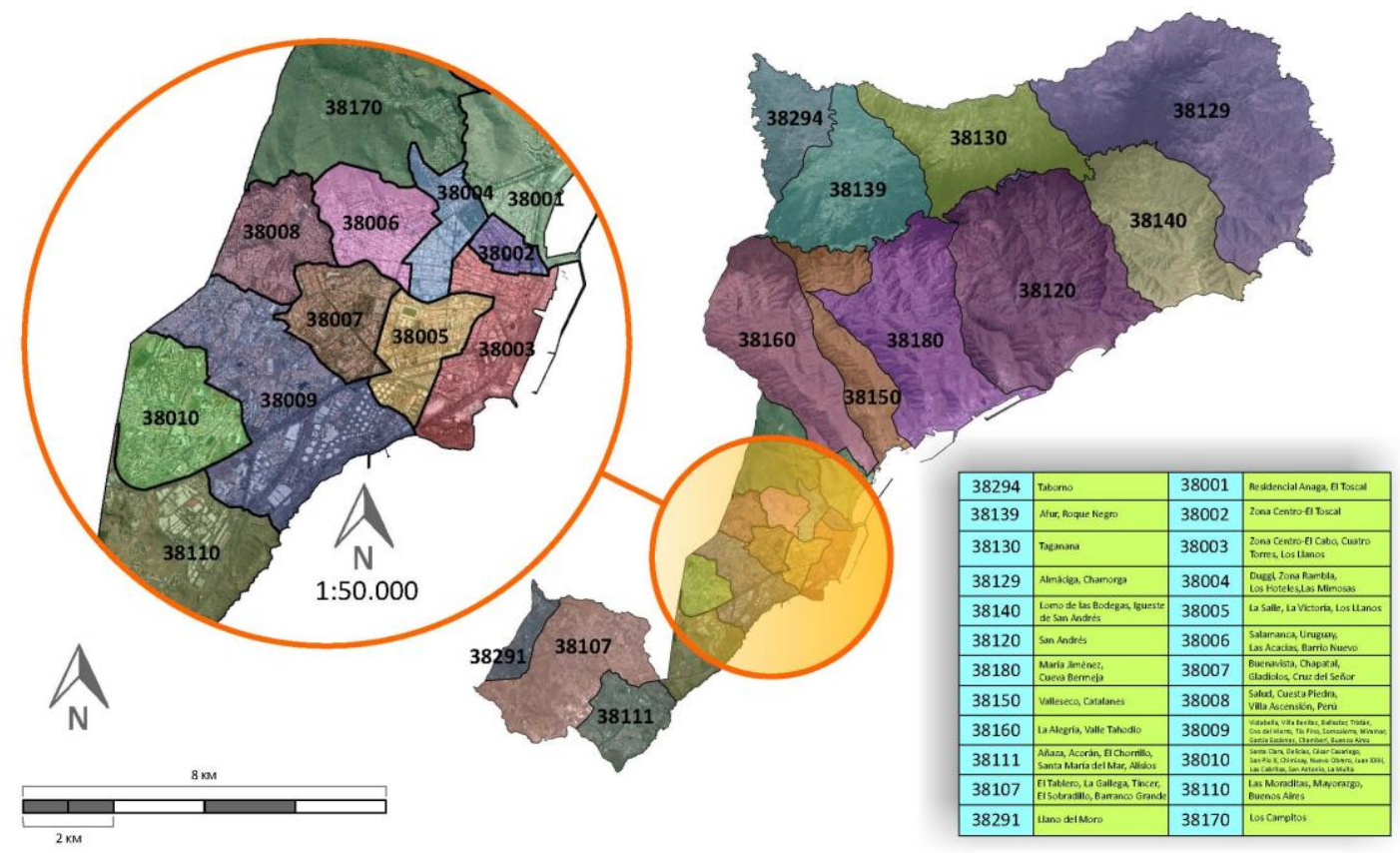

Fuente: Observatorio Socioeconómico de la Sociedad de Desarrollo de Santa Cruz de Tenerife. Elaboración propia.

Con 223.185 habitantes (Observatorio Socioeconómico de la Sociedad de Desarrollo de Santa Cruz de Tenerife), el término municipal se encuentra dividido en 5 Distritos administrativos: Distrito Anaga, Distrito Centro - Ifara, Distrito Salud - La Salle, Distrito Ofra - Costa Sur y Distrito Suroeste. 


\section{Figura 2. Distribución porcentual de la población del municipio de Santa Cruz de Tenerife en 2012}

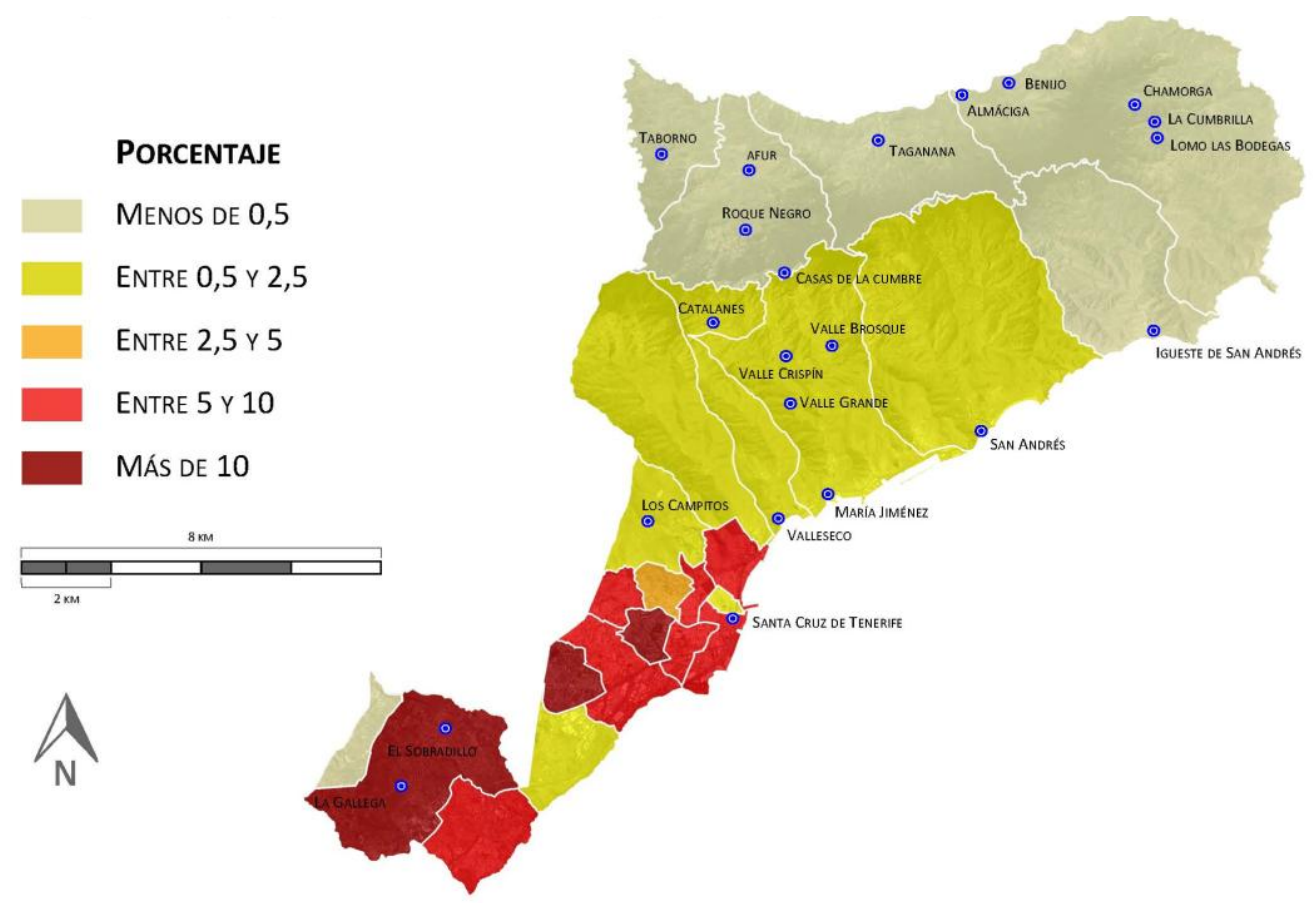

Fuente: Observatorio Socioeconómico de la Sociedad de Desarrollo de Santa Cruz de Tenerife. Elaboración propia.

Como podemos apreciar en el mapa representado en la fig. 2, la población se distribuye de manera desigual condicionada por el relieve, concentrándose la mayoría en el sector más llano de la ciudad correspondiente a la rampa lávica y en las medianías del margen suroeste, único lugar posible de expansión, debido a la presencia de la refinería hacia el sur y el macizo de Anaga al noreste. Sin embargo, no sólo el relieve explica esa distribución actual de la población, sino que la formación de la ciudad marginal, llamada de esta forma, no por hacer semejanza con la marginalidad en sí, sino por haber surgido en los márgenes de la ciudad, eso sí, construida fuera de ordenación y perteneciente a las clases menos pudientes, fueron ocupando sectores en las laderas de las montañas de Anaga, como es el caso del Barrio de Alegría o Barrio Nuevo, y laderas y desembocaduras de barrancos del macizo, como es San Andrés, Valleseco o María Jiménez.

Pero, fue a partir del puerto, si nos remontamos a los orígenes de la formación de la ciudad, que se empieza a construir la misma. En torno a éste aparece el núcleo primitivo de población y, seguidamente, el casco urbano. Alrededor del cual, a excepción de Ifara, que se sitúa en una ladera, se forman grandes conjuntos residenciales y se encuentra la población con mayores ingresos.

El resto de la población se distribuye, a partir del casco urbano o zona centro, en edificaciones sin solución de continuidad que forman barrios y barriadas en dirección hacia el municipio de La Laguna aprovechando la carretera Santa Cruz - La Laguna. La Cuesta es el principal eje comunicativo que une ambas ciudades y, como su nombre 
indica, se trata de un sector asentado sobre un plano inclinado con bastante pendiente o desnivel. El otro gran ingente poblacional es el que encontramos paralelo a la Carretera del Rosario, donde se crearon algunos barrios y barriadas que fueron creciendo para albergar a trabajadores de la refinería.

Una de las primeras conclusiones que extrapolamos y que llama poderosamente la atención sobre la distribución de la población y, que podemos confirmar según el mapa anterior, se trata de la desigual distribución del suelo, cuyo reparto histórico se encuentra recogido en diversas publicaciones de índole científico y libros de interés, como por ejemplo: Santa Cruz de Tenerife, la formación de la ciudad marginal (García Herrera, 2005), Construir la Ciudad: criterios, objetivos y soluciones generales para la revisión del Plan General de Ordenación Urbana sobre el crecimiento de la ciudad de Santa Cruz de Tenerife o La clase obrera en Santa Cruz de Tenerife (tesis doctoral del historiador Rayco Rodríguez Trujillo), y que si no nos hablan directamente sobre éste, si nos pueden dar pistas sobre esta idea. No obstante, sin detenernos mucho en esta cuestión puesto que no es el objeto fundamental del trabajo, si es interesante esta conclusión para el entendimiento de cómo se ha ido construyendo la pobreza en esta ciudad.

Tras largas décadas de un aparente "sostenible crecimiento económico" de la ciudad de Santa Cruz de Tenerife, ciudad post agraria, dedicada casi en exclusiva desde esos años y hasta la actualidad al sector servicios y al subsector de la construcción, las existentes bolsas de pobreza y marginación, parecieron quedar olvidadas e ignoradas eclipsadas por ese crecimiento y bienestar.

Paralelamente a la llegada de la crisis económica del capitalismo esas bolsas de pobreza y marginación comenzaron a experimentar un crecimiento, al mismo ritmo que crecían las cifras del paro y la destrucción de contratos.

Si hablamos en números absolutos, en el periodo de 2005 hasta 2013, diciembre de 2006 con 12.018 parados (Observatorio Socioeconómico de la Sociedad de Desarrollo de Santa Cruz de Tenerife), registraba el número de los mismos más bajo de este periodo, mientras que abril de 2013, con 29.889 (Observatorio Socioeconómico de la Sociedad de Desarrollo de Santa Cruz de Tenerife), supone el mes con mayor número de parados. Esta evolución de 17.871 parados, más del doble en apenas 7 años, es muy significativa a la hora de relacionar el incremento de la pobreza y el desempleo. 
Figura 3. Evolución porcentual del número de parados entre el 31 de diciembre de 2005 y el 31 de diciembre de 2012

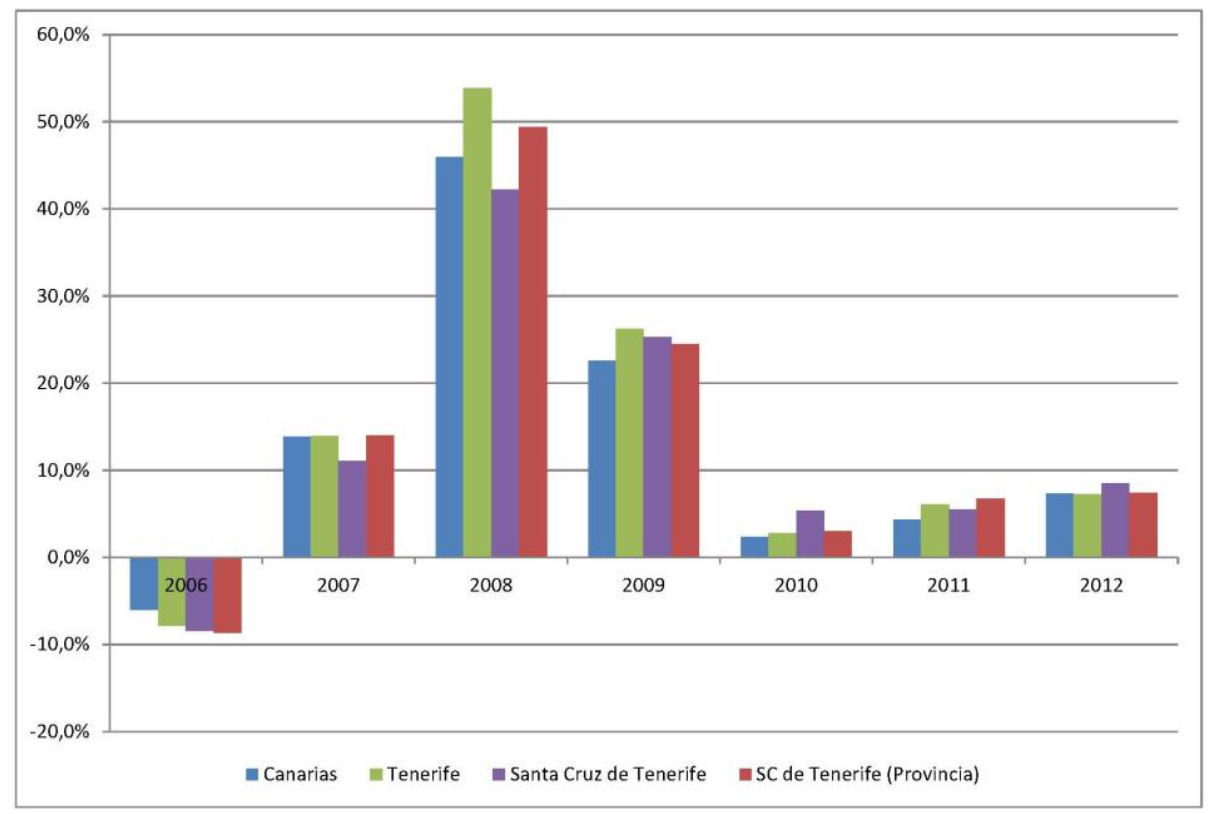

Fuente: Observatorio Socioeconómico de la Sociedad de Desarrollo de Santa Cruz de Tenerife. Elaboración propia

Pero para hacer comparativas con el resto de la región tenemos que hablar en términos porcentuales. Si observamos el gráfico de la fig. 3., a pesar de que existe un considerable crecimiento en el porcentaje de parados en 2007, es en 2008 el momento en que se dispara dicho crecimiento, coincidiendo con el primer año de la crisis. El porcentaje de parados con respecto al año anterior no ha dejado de aumentar desde entonces. Este aumento comenzaba en 2007, curiosamente, el municipio de Santa Cruz de Tenerife con respecto a Canarias, a la provincia y a la isla experimentaba el menor crecimiento porcentual en ese año; en 2012 la situación se invertía y el municipio se sitúa a la cabeza de ese crecimiento. Sea como sea, el porcentaje de parados no cesa de aumentar con respecto al año anterior.

Con respecto a la disminución de contratos, queda patente, en este gráfico como en el anterior, que los sectores productivos: construcción y sector servicios, que sustentaban la economía canaria significaron un espejismo y una falta de respuesta a la crisis del sistema capitalista. La destrucción de empleos no ha parado de acrecentarse desde el comienzo de la misma. Con la salvedad de que en 2010 aumentó ligeramente el porcentaje de generación de contratos, en Canarias un 7\%, a lo cual podría dar respuesta un estudio de mercado, lo cierto es que la tendencia es negativa y el porcentaje de número de contratos no deja de descender año tras año. El municipio de Santa Cruz de Tenerife con respecto a Canarias, a la provincia y a la isla experimenta, para 2012, el mayor número de disminución de contratos en términos porcentuales. Los 682 contratos indefinidos (Observatorio Socioeconómico de la Sociedad de Desarrollo de Santa Cruz de Tenerife) de diciembre de 2005 han disminuido, para ser tan sólo 500 los indefinidos (Observatorio Socioeconómico de la Sociedad de Desarrollo de Santa Cruz de Tenerife) de mayo de 2013; tan sólo esta cifra supone "la población trabajadora siempre 
empleada" del municipio, mientras que los 4.686 contratos de duración determinada (Observatorio Socioeconómico de la Sociedad de Desarrollo de Santa Cruz de Tenerife) a mayo del presente año no hacen más que sumarse a una lista de empleados eventuales, empleados irregulares, parados, en prácticas, etc., y todas aquellas modalidades de precarización laboral o ausencia de ésta que suponen "la sobrepoblación relativa". Cuanto mayor es esta última, mayores consecuencias económicas y sociales padecerá la población del municipio.

Figura 4. Evolución porcentual del número de parados entre el 31 de diciembre de 2005 y el 31 de diciembre de 2012

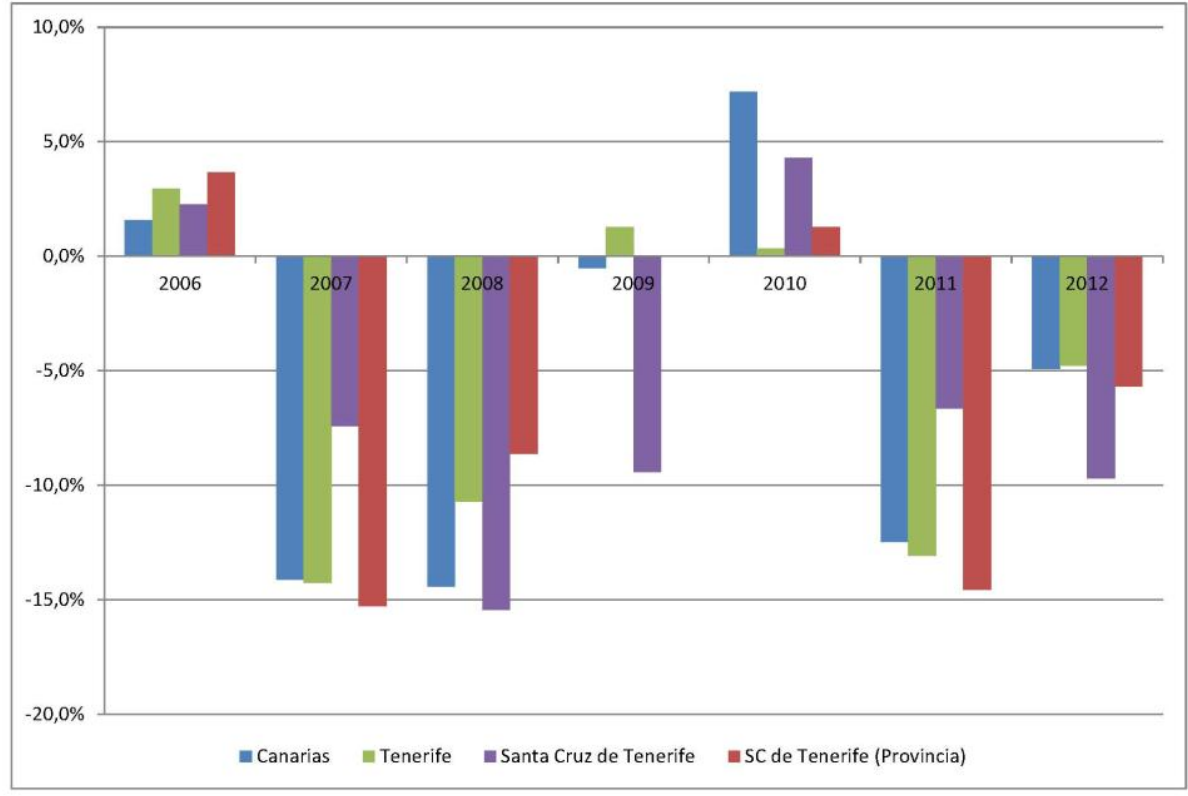

Fuente: Observatorio Socioeconómico de la Sociedad de Desarrollo de Santa Cruz de Tenerife. Elaboración propia.

Los demandantes de empleo, es decir, todos aquellos que realizan una solicitud de un puesto de trabajo en una oficina del INEM, de la ciudad en 2012, se repartieron como podemos ver en el mapa de la fig. 5. Siendo más numerosos en el sector suroeste de la ciudad, que como veremos en las siguientes gráficas suponen la zona con mayor riesgo de exclusión coincidiendo con las zonas dónde mayor paro registrado existe. 
Figura 5. Distribución de los demandantes de empleo en el municipio de Santa Cruz de Tenerife en 2012

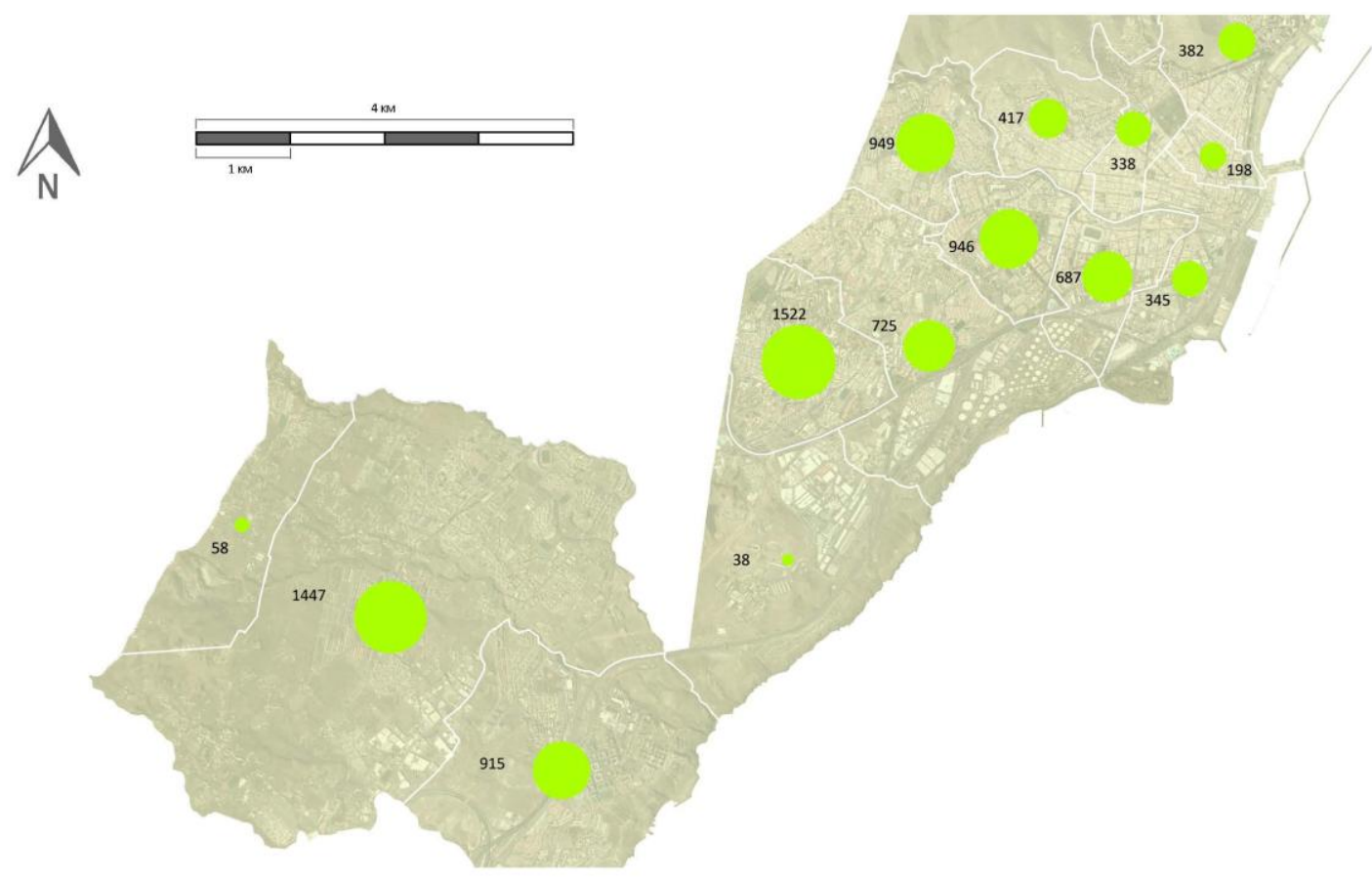

Fuente: Observatorio Socioeconómico de la Sociedad de Desarrollo de Santa Cruz de Tenerife. Elaboración propia.

Entrelazando las variables de edad: menores de 25 , de 25 a 45 y mayores de 45 ; de sexo; de nivel de formación: personas analfabetas, educación primaria (completa o incompleta), educación secundaria, formación profesional y titulación universitaria; de la clasificación utilizada por OBECAN para los sectores económicos de su último contrato: Sin Actividad Económica, Agricultura, Industria, Construcción, Comercio, Hostelería, Resto de Servicios; y de duración de la demanda de empleo: menos de un año, hasta 2 años y más de 2 años. Agrupando las distintas personas residentes en Santa Cruz de Tenerife registradas en situación de paro por el Servicio Canario de Empleo. El Observatorio Socioeconómico de la Sociedad de Desarrollo de Santa Cruz de Tenerife, establece la clasificación cuyo promedio mensual de casos en 2012 fue más numeroso. Basándonos en dicha clasificación se representan los diversos colectivos: 


\section{Cuadro 1. Principales agrupaciones empleadas por El Observatorio Socioeconómico de la Sociedad de Desarrollo de Santa Cruz de Tenerife}

\begin{tabular}{|c|c|}
\hline COLECTIVOS & $\begin{array}{l}\text { Principales agrupaciones de variables empleadas por El } \\
\text { Observatorio Socioeconómico de la Sociedad de Desarrollo de } \\
\text { Santa Cruz de Tenerife. }\end{array}$ \\
\hline Colectivo 1 & $\begin{array}{l}\text { Mujer, entre } 25 \text { y } 45 \text { años, con formación en secundaria y } \\
\text { experiencia en los servicios (Resto de servicios), con menos de un } \\
\text { año en paro. }\end{array}$ \\
\hline Colectivo 2 & $\begin{array}{l}\text { Mujer mayor de } 45 \text { años, sin formación pero con experiencia en los } \\
\text { servicios (Resto de servicios), con más de } 2 \text { años sin formalizar un } \\
\text { contrato. }\end{array}$ \\
\hline Colectivo 3 & $\begin{array}{l}\text { Hombre de más de } 45 \text { años, sin formación, ex trabajador de la } \\
\text { construcción y con más de } 2 \text { años en paro. }\end{array}$ \\
\hline Colectivo 4 & $\begin{array}{l}\text { Hombre entre } 25 \text { y } 45 \text { años, sin formación, ex trabajador de la } \\
\text { construcción, con menos de un año en paro. }\end{array}$ \\
\hline Colectivo 5 & $\begin{array}{l}\text { Hombre, entre } 25 \text { y } 45 \text {, con formación en secundaria y experiencia } \\
\text { en los servicios (Resto de servicios) y menos de un año buscando } \\
\text { empleo. }\end{array}$ \\
\hline Colectivo 6 & $\begin{array}{l}\text { Mujer, entre los } 25 \text { y } 45 \text { años, sin formación aunque con } \\
\text { experiencia en los servicios (Resto de servicios) y menos de un año } \\
\text { parada. }\end{array}$ \\
\hline Colectivo 7 & $\begin{array}{l}\text { Mujer, entre } 25 \text { y } 45 \text { años, universitaria y con experiencia en los } \\
\text { servicios (Resto de servicios), y menos de un año buscando trabajo. }\end{array}$ \\
\hline Colectivo 8 & $\begin{array}{l}\text { Hombre, entre } 25 \text { y } 45 \text { años, sin formación pero con experiencia en } \\
\text { los servicios (Resto de servicios) y menos de un año en paro. }\end{array}$ \\
\hline Colectivo 9 & $\begin{array}{l}\text { Hombre mayor de } 45 \text { años, sin formación, ex trabajador de los } \\
\text { servicios (Resto de servicios), con más de } 2 \text { años, buscando trabajo. }\end{array}$ \\
\hline
\end{tabular}

Fuente: Observatorio Socioeconómico de la Sociedad de Desarrollo de Santa Cruz de Tenerife.

Elaboración propia. 
Figura 6. Colectivo 1: Distribución porcentual en el municipio de Santa Cruz de Tenerife

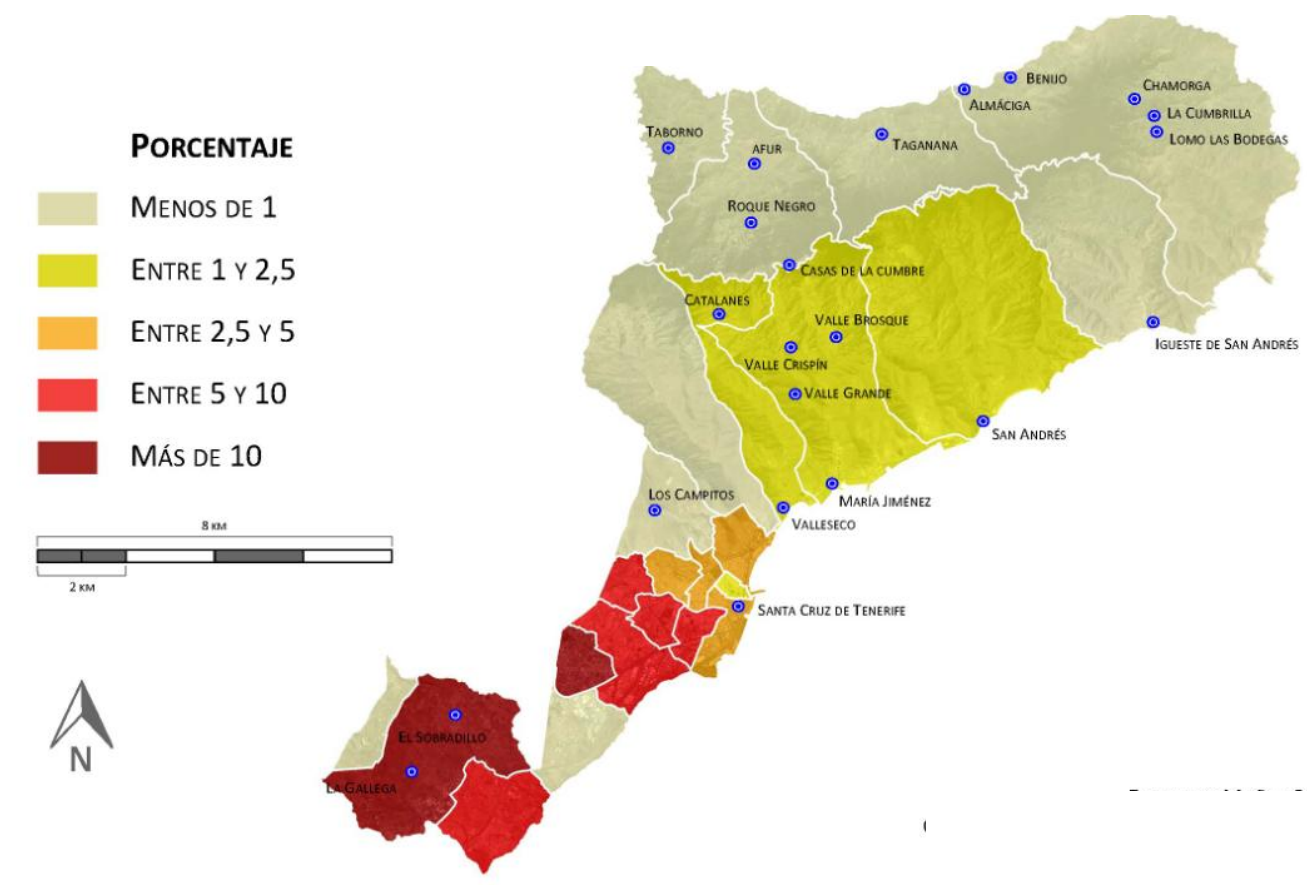

Fuente: Observatorio Socioeconómico de la Sociedad de Desarrollo de Santa Cruz de Tenerife. Elaboración propia.

Figura 7. Colectivo 2: Distribución porcentual en el municipio de Santa Cruz de Tenerife

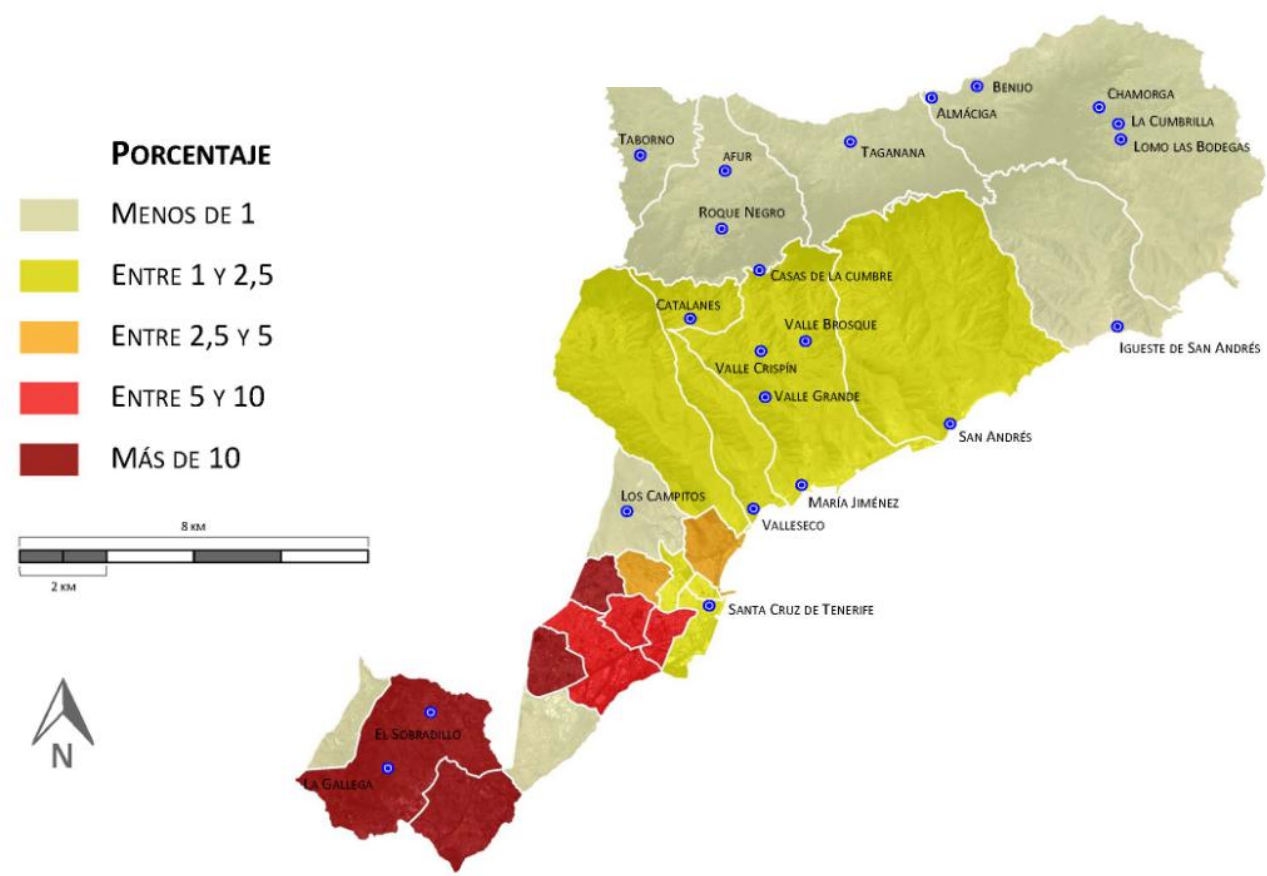

Fuente: Observatorio Socioeconómico de la Sociedad de Desarrollo de Santa Cruz de Tenerife. Elaboración propia. 
Figura 8. Colectivo 3: Distribución porcentual en el municipio de Santa Cruz de Tenerife

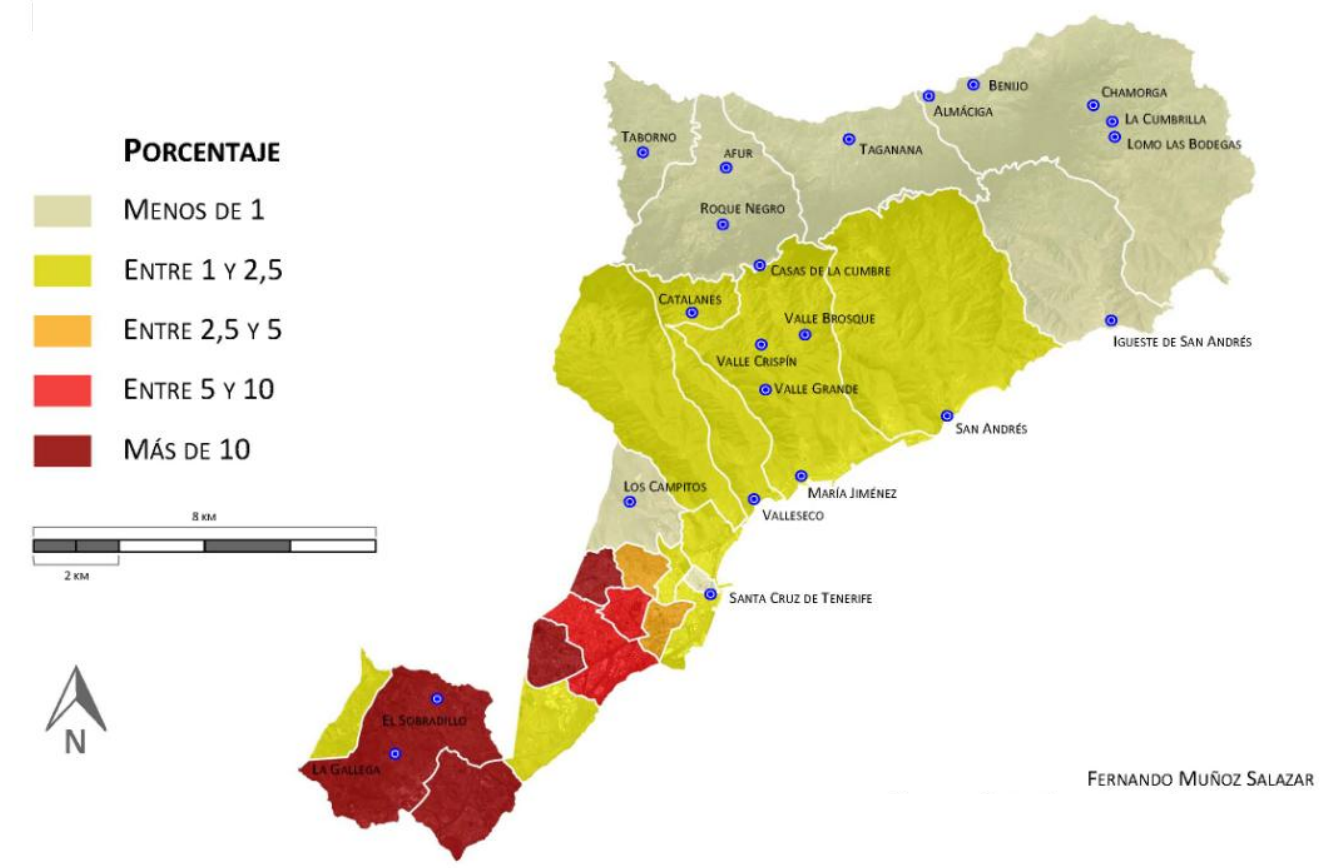

Fuente: Observatorio Socioeconómico de la Sociedad de Desarrollo de Santa Cruz de Tenerife. Elaboración propia.

\section{Figura 9. Colectivo 4: Distribución porcentual en el municipio de Santa Cruz de Tenerife}

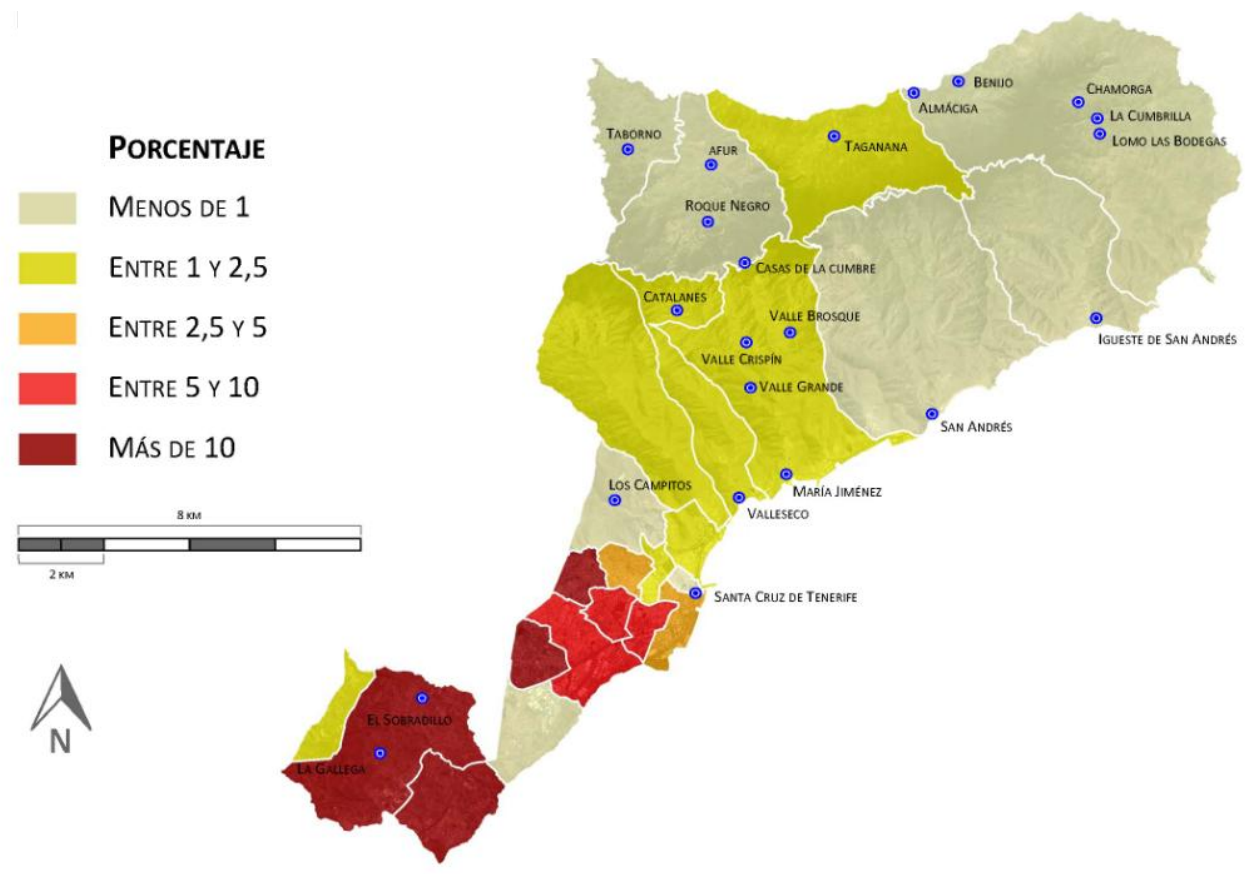

Fuente: Observatorio Socioeconómico de la Sociedad de Desarrollo de Santa Cruz de Tenerife. Elaboración propia. 
Figura 10. Colectivo 5: Distribución porcentual en el municipio de Santa Cruz de Tenerife

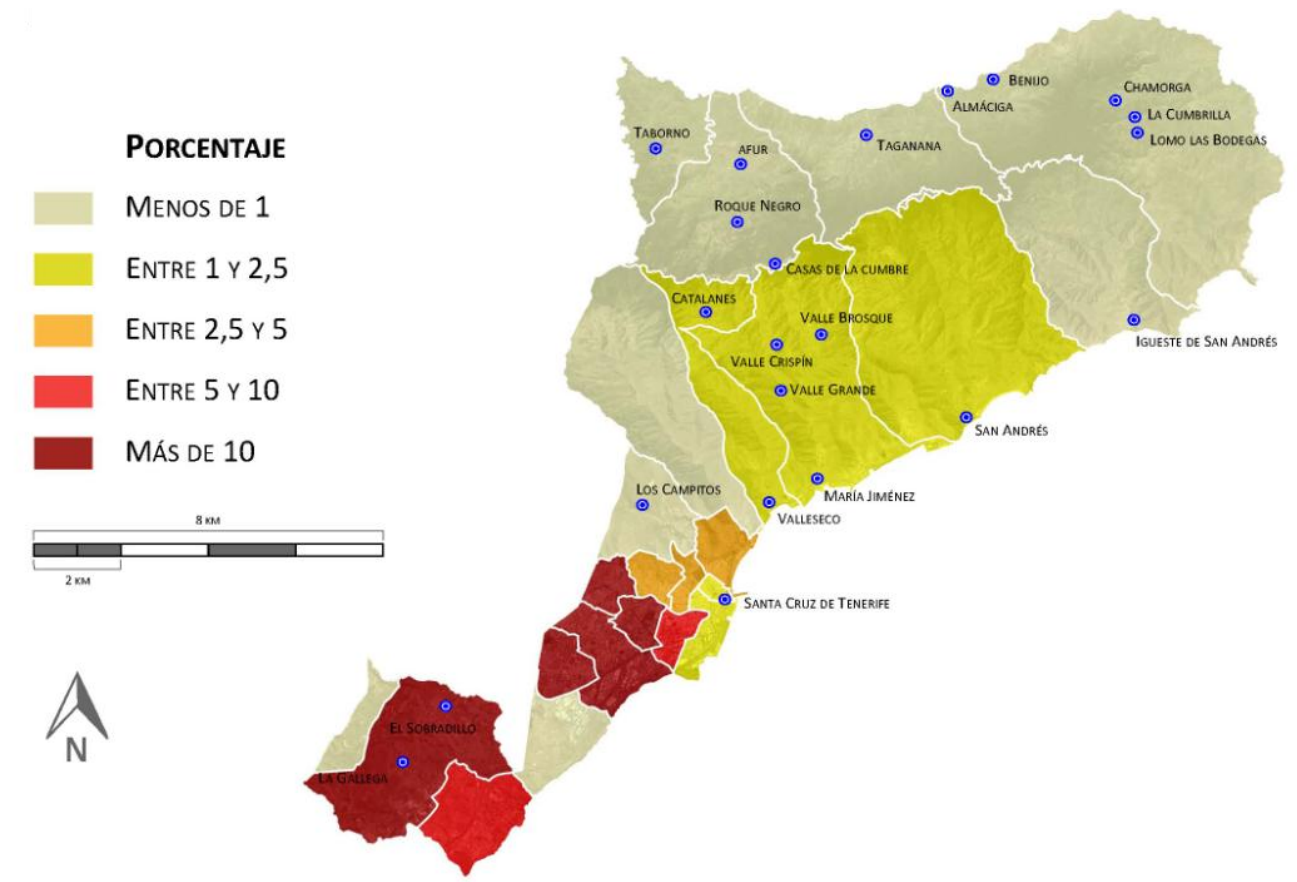

Fuente: Observatorio Socioeconómico de la Sociedad de Desarrollo de Santa Cruz de Tenerife. Elaboración propia.

Figura 11. Colectivo 6: Distribución porcentual en el municipio de Santa Cruz de Tenerife

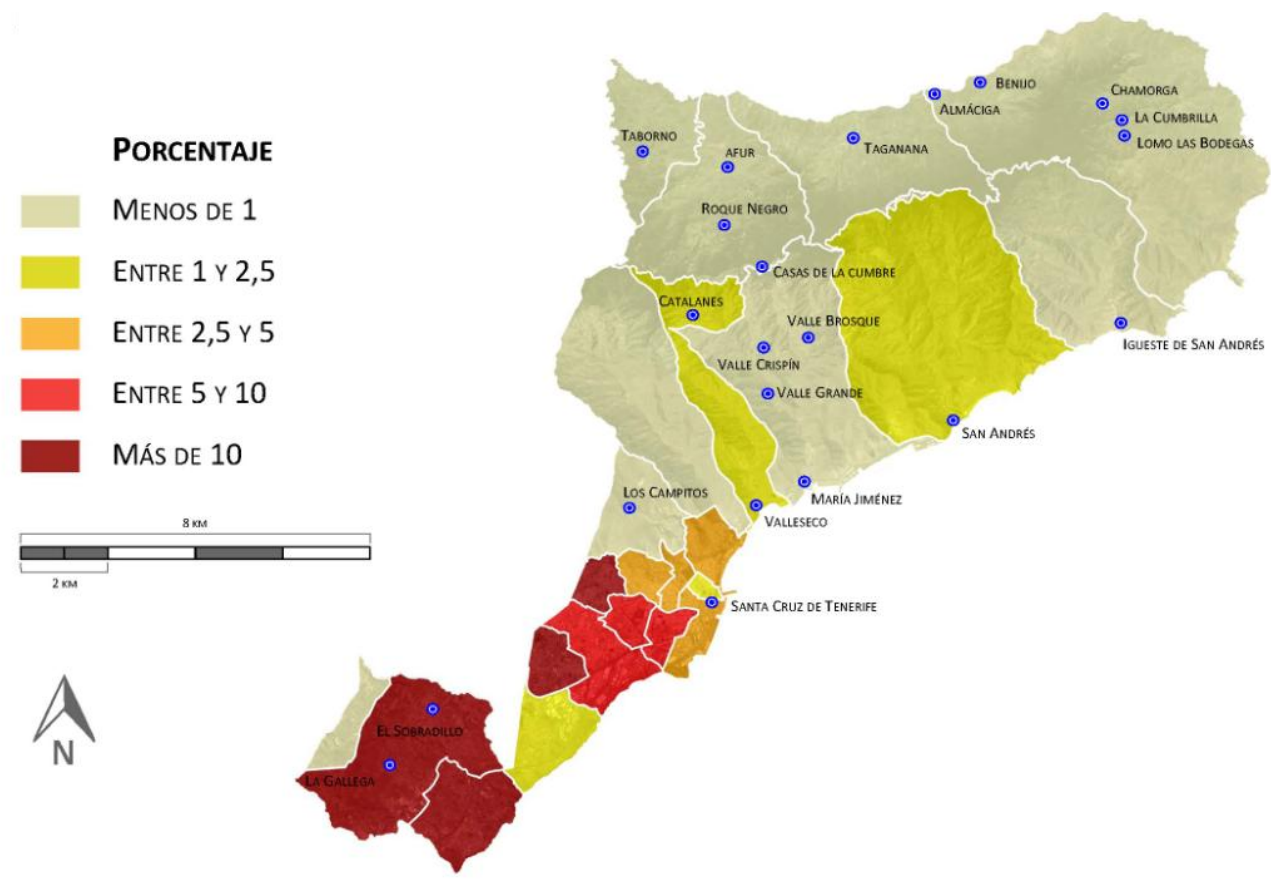

Fuente: Observatorio Socioeconómico de la Sociedad de Desarrollo de Santa Cruz de Tenerife. Elaboración propia. 
Figura 12. Colectivo 7: Distribución porcentual en el municipio de Santa Cruz de Tenerife

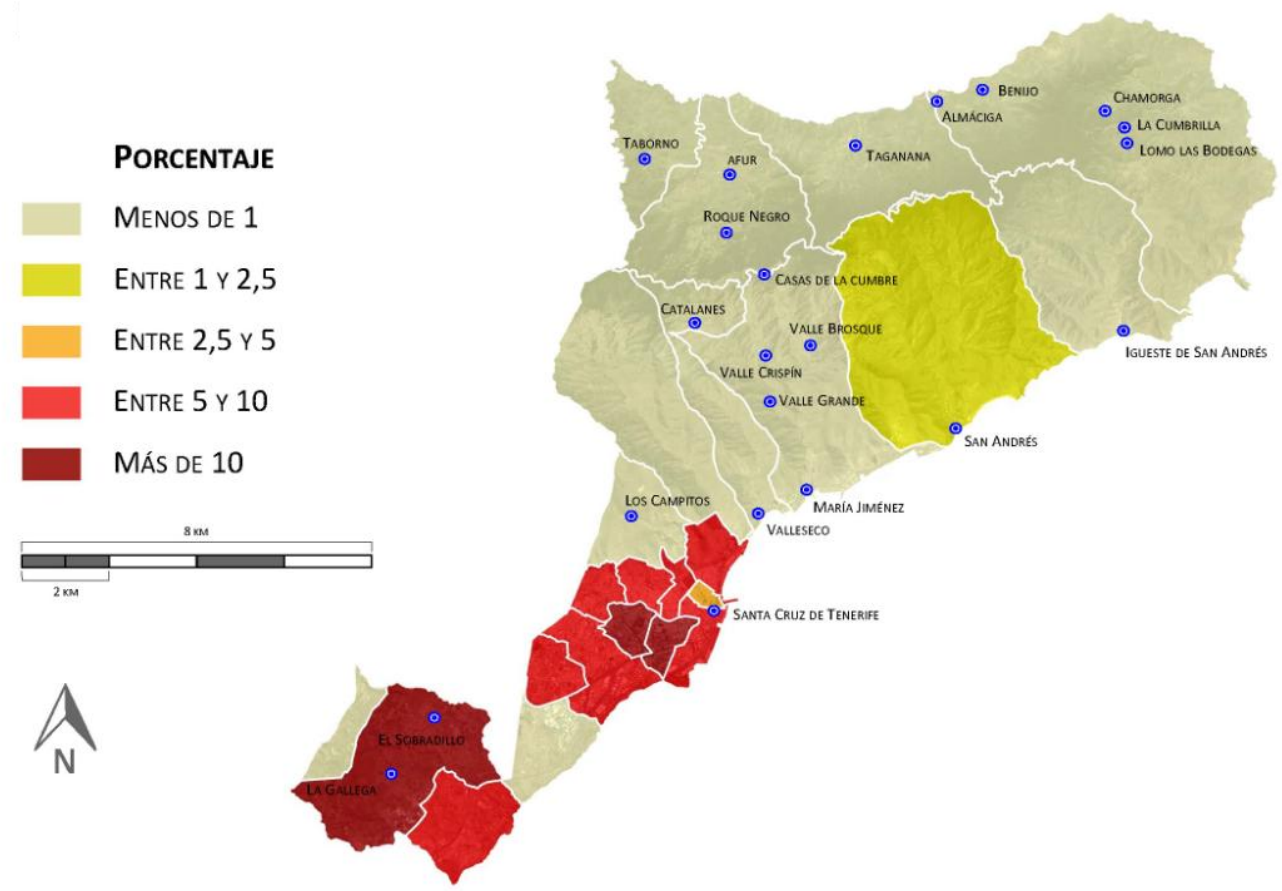

Fuente: Observatorio Socioeconómico de la Sociedad de Desarrollo de Santa Cruz de Tenerife. Elaboración propia.

Figura 13. Colectivo 8: Distribución porcentual en el municipio de Santa Cruz de Tenerife

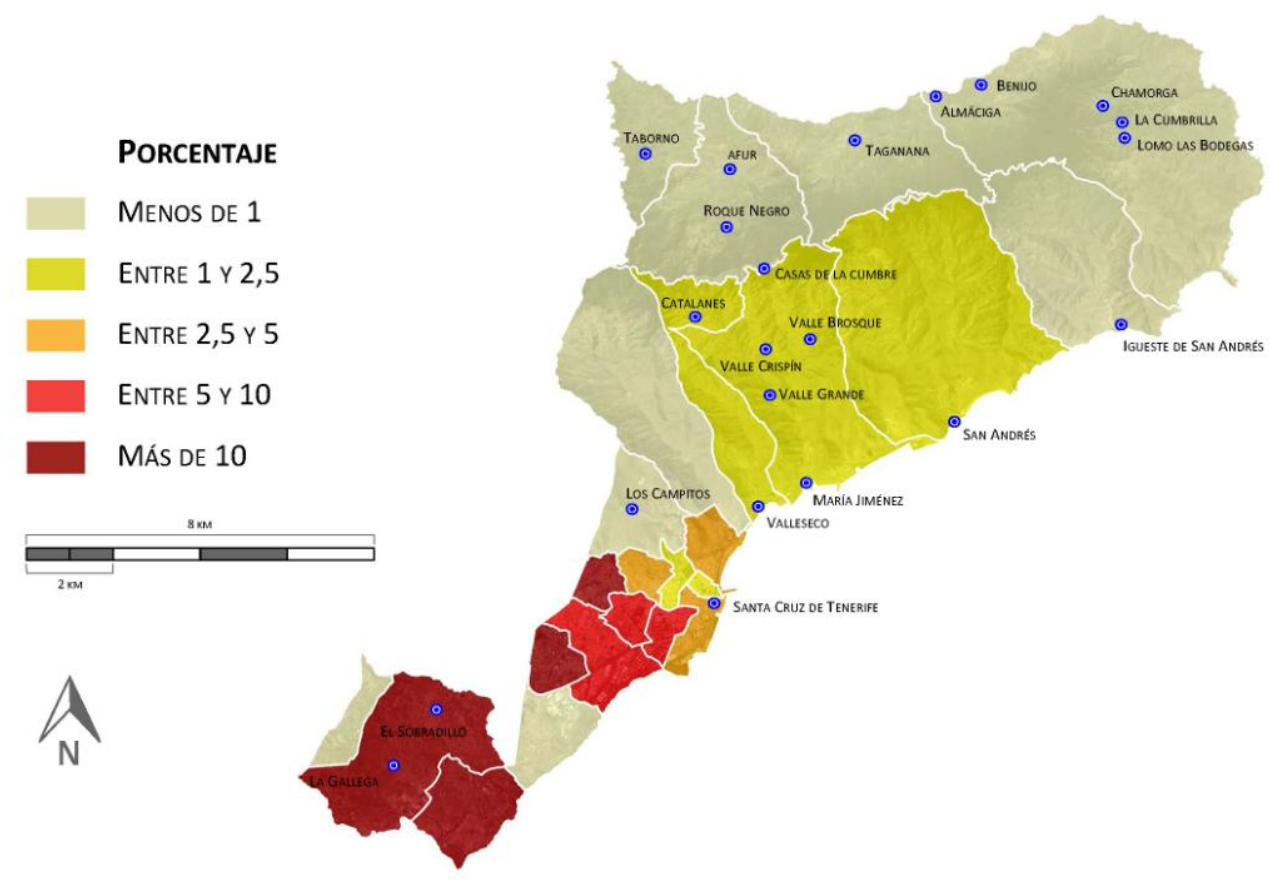

Fuente: Observatorio Socioeconómico de la Sociedad de Desarrollo de Santa Cruz de Tenerife. Elaboración propia. 


\section{Figura 14. Colectivo 9: Distribución porcentual en el municipio de Santa Cruz de Tenerife}

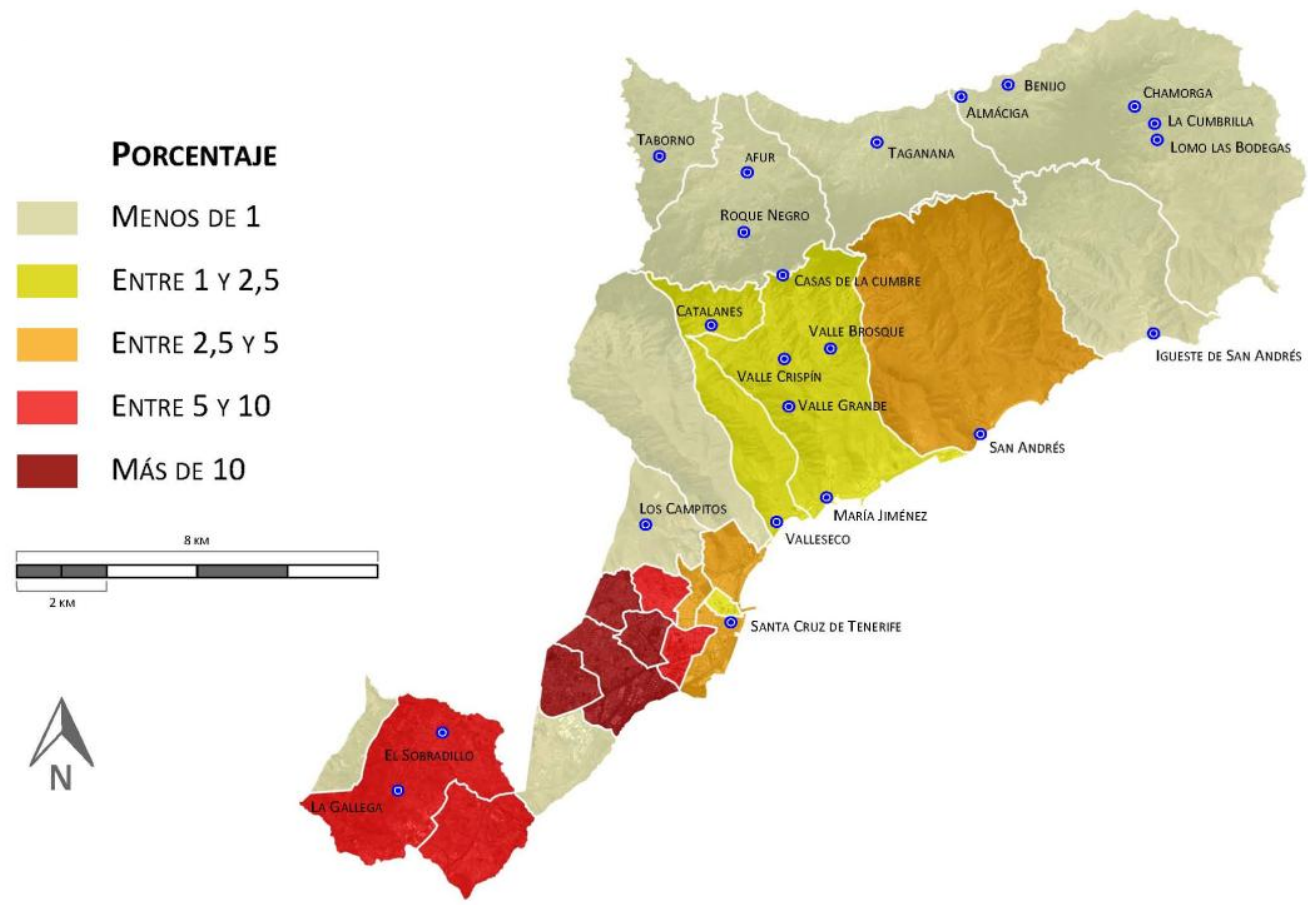

Fuente: Observatorio Socioeconómico de la Sociedad de Desarrollo de Santa Cruz de Tenerife. Elaboración propia.

Porcentualmente, los colectivos con más problemas de inserción laboral, es decir, los representados anteriormente, se distribuyen por el municipio de manera desigual, y a excepción de la fig. 14., son los más presentes en los barrios integrados en la agrupación de los códigos postales 38.111 y 38.107 , que abarca la mayoría del sector suroeste del municipio. Esta zona de la ciudad, no sólo coincide en aglutinar los colectivos más vulnerables, siendo el colectivo 3 (hombre de más de 45 años, sin formación, ex trabajador de la construcción y con más de 2 años en paro) el que más ha crecido en términos relativos en el último año y el que en principio será más complicado para encontrar trabajo debido a su déficit de cualificación, además, se trata de la zona de más demandantes de empleo y mayores tasas de paro. Otra información de tipo cualitativo extraída de la entrevista con la Sra. D ${ }^{a}$ Alicia Álvarez González, Concejala de Gobierno del Área de Atención Social y Servicios Personales, confirmaba que esta zona del municipio era la más vulnerable y la que más casos de exclusión social estaba presentando, coincidiendo con la zona donde más parejas jóvenes y desempleados, ex trabajadores de la construcción había. Esto no viene sino a reforzar dos cosas, que el sector servicios y el subsector de la construcción, principales sectores productivos del municipio, eran frágiles e insuficientes, y que el desempleo está estrechamente ligado con el incremento de la pobreza. En la entrevista con Sr. Jesús Manuel Gil Agüín, que ha ejercido como párroco en cuatro parroquias del municipio (Chamberí, Cabo Llanos, El Sobradillo y Llano del Moro) aportaba que a diferencia de la pobreza espiritual, más presente en Cabo Llanos, la pobreza material se consolidaba, sobre todo, en la zona del Sobradillo. 
Todo este este análisis cuantitativo, arroja inevitablemente, la cruda realidad de unos datos que han sido recogidos por el Informe de Intervención Social de 2012 del Instituto Municipal de Atención Social (IMAS) y en los informes de sus diferentes Unidades de Trabajo Social (UTS) de cada distrito. En ellos destacan las características de la población que acude a los servicios sociales, que presentan, entre otras, un claro empobrecimiento, exclusión del mercado laboral, dependencia de ingresos de prestaciones sociales y ausencia/inexistencia de ingresos una vez finalizadas las prestaciones sociales; dificultad para la integración laboral (desempleo de larga duración, trabajo precario, trabajo empobrecedor); dificultad de acceso a la educación y los mínimos educativos (fracaso escolar); inadecuación de la formación (con respecto a los sectores en donde se demandan puestos de trabajo) y dificultades para la formación continua; insuficiencia de plazas alojativas para personas en alta exclusión social, alojamientos compartidos, infraviviendas, deterioro general del alojamiento; carencia de salud, de capacidad psico-física y de asistencia sanitaria a colectivos en situación de exclusión social (personas sin hogar, inmigrantes...) y ausencia o insuficiencia de apoyos familiares o comunitarios.

En resumen, el número de atenciones se ha incrementado, se ha mantenido constante el incremento de éstas y parece no parar de aumentar, al menos a corto - medio plazo. Lo cual no sorprende si atendemos al contenido de fondo presentado durante todo el trabajo.

\section{CONCLUSIONES}

Esta investigación no ha pretendido ni presentar unos resultados indiscutibles ni aportar las claves para solventar el problema de la pobreza en el municipio de Santa Cruz de Tenerife. No obstante, analizada toda la información cuantitativa y cualitativa empleada para su estudio, hemos podido poner de manifiesto que la precarización laboral en todas sus manifestaciones, las elevadas tasas de desempleo y las diversas formas de déficit laborales que presenta el municipio, establece un vínculo directo entre mercado laboral, es decir, las relaciones de producción y las condiciones materiales de existencia del proletariado, que actualmente han decaído notablemente, y su manifestación última que es la pobreza. Esta relación cumple el objetivo central del estudio, además, de ella deducimos que el aumento de la pobreza en Santa Cruz responde perfectamente a una crisis sistémica global, sólo que aquí, se ha visto exacerbada por unos condicionantes. Dichos condicionantes han sido tratados de manera genérica a lo largo del trabajo, debido a la envergadura y al calado de la materia a tratar, quedando inconcluso éste en cuanto a lo que se aspira. Las especificidades no sólo de cada condicionante, sino de cada sector del municipio debieran requerir un estudio paralelo, que desde lo general conjugue lo específico, así pues, la segunda parte del trabajo sólo supone un aplazamiento del mismo.

$1^{\circ}$. El aumento de la pobreza en Santa Cruz responde perfectamente a una crisis sistémica global.

En el año 2002, en el informe: Ciudad Oscura, Ciudad Luminosa Santa Cruz de Tenerife, los profesores Díaz Rodríguez, Delgado Acosta, Calero Martín, García 
Herrera, Pérez Pérez y Mejías Vera, del departamento de Geografía de la ULL concluían el mismo afirmando que: "En definitiva, las recientes actuaciones urbanísticas originan en Santa Cruz de Tenerife un proceso de doble dimensión: Por un lado, la aparición de una ciudad remodelada, embellecida, con intención de ser competitiva en el mercado urbano global; por otro, en la trastienda urbana local, se consolida la marginación social y se acentúan la exclusión y la pobreza". Pasados 11 años esa trastienda se ha destapado, y la consolidación de la pobreza se evidencia en conjunción con la crisis del sistema. Además, la ocupación del suelo ha ido en contra de los principios básicos de equidad en todo el municipio, presentando unos desequilibrios patentes en su distribución y uso, causada porque esos principios han sido suplantados por los de rentabilidad económica, teniendo que ocupar las clases populares las tierras, parcelas y solares más económicos y en los lugares de la topografía más accidentada de Santa Cruz. Esa segregación socio-espacial de la ciudad, presenta unos indicadores de desempleo y precariedad, como hemos visto, en aquellas zonas ocupadas por la clase obrera, correspondiente a toda la periferia del municipio y a los núcleos que se integran en las laderas y el macizo de Anaga, circunstancias éstas que evidencian que el injusto reparto del suelo ha generado pobreza en muchas zonas del municipio.

$2^{\circ}$. El poco equitativo reparto del suelo ha generado bolsas de marginalidad en muchos sectores de la ciudad que han contribuido en consolidar la pobreza.

Por medio de los argumentos y conclusiones que se presentan en esta investigación, se pretende, no sólo derribar algunas sentencias, que intencionadamente o no, algunos demuestran en sus consideraciones interesadas acerca de la causalidad y existencia de la pobreza en el municipio, además, pretendemos que los estudios existentes sobre la misma se incrementen y enriquezcan por medio de la investigación científica. La posibilidad de aplicar científicamente los conceptos marxistas de la renta de la tierra y del capital, sobre un espacio eminentemente urbano, nos posibilita el entendimiento e interpretación de la generación, crecimiento y establecimiento del hecho de la pobreza en el ámbito de estudio.

$3^{\circ}$. El método científico marxista explica y da respuesta al hecho de la pobreza en el municipio de Santa Cruz de Tenerife.

Son múltiples los motivos que impiden resolver el problema de la pobreza. Sus limitaciones, no sólo se ciñen al problema de su conceptualización y de su descripción, y desde luego, no sólo debemos anclarnos en estos aspectos a la hora de abordar la cuestión. La pobreza no se define de una única manera, depende en gran medida del enfoque de quien la conceptualice y de la reflexión que se tenga sobre sus causas. Si bien su multidimensionalidad hace acrecentar la dificultad del entendimiento de dicho problema, al menos, su causalidad parece no ser tan múltiple. Y ese propósito se ha perseguido durante toda la investigación, la realización y la presentación de este trabajo. Después del mismo, no sólo me reafirmo en el posicionamiento de mi enfoque, sino que además avalo con la presentación de los datos cuantitativos y con el conocimiento empírico de la materia que la investigación me ha proporcionado, que las causas de la pobreza radican en el sustento del modelo capitalista aplicado al trabajo y más 
concretamente, sobre las reformas neoconservadoras, que acentúan aún más si cabe estas causas.

\section{$4^{\circ}$. Eliminar la pobreza pasa por eliminar sus causas.}

Las soluciones para la disminución de la pobreza que se dan actualmente son variadas. Desde las ONG más importantes en el tratamiento de la pobreza y desde la Iglesia Católica, sobre todo, se propone en gran medida la caridad, las ayudas y la beneficencia como parte de las posibles soluciones. Multitud de ejemplos podemos encontrar en la prensa sobre este asunto; promover campañas de concienciación social, telemaratones de recogida de alimentos, etc., además, muchas instituciones participan como colaboradoras de este tipo de eventos; que sin solucionar las causas de la pobreza, aportan una solución a corto plazo. En el Informe de la fundación Foessa 2013 o en el VII informe del Observatorio de la realidad social (Cáritas. 2012), se concluye asegurando además, qué: “Una vez más afirmamos que no es sólo la coyuntura de la crisis, sino la estructura con la que se está configurando y blindando el sistema de protección social, la que deja fuera a los grupos más empobrecidos y excluidos de la sociedad". Esta misma línea es la que propugnan los múltiples informes y el resto de instituciones reformistas, ONU, Banco Mundial, y un largo etc., que afirman que se requiere una mayor intervención del Estado en la economía. Los neoliberales, por su parte, dicen directamente que esta problemática se solucionará con las políticas de reajustes en los mercados y con el paso del tiempo.

Las crisis no pasan porque pase el tiempo, pasan porque cambian las políticas económicas, las condiciones laborales y, sobre todo, porque el sistema productivo también cambia para fomentar el trabajo. Este sistema no es re-fundable, a los datos y a las crisis me remito. Esta última, no ha hecho más que confirmar las últimas consecuencias del mismo presentando una mayor acumulación del capital, es decir, una acumulación creciente de la riqueza social en una parte cada vez menor de la población, que pertenece a la clase capitalista (en un artículo publicado en el periódico Público por Vicenç Navarro el 29 de diciembre de 2011, señala que según los últimos estudios de la distribución de la riqueza y de las rentas en EEUU, el 1\% de la población posee el $40 \%$ de toda la riqueza -era el $33 \%$ hace 25 años- y el $42 \%$ de todas las acciones e instrumentos bancarios que generan dinero), mientras simultáneamente hay un crecimiento de la población desocupada y el consiguiente incremento de la pobreza relativa del resto de la población que pertenece a la clase trabajadora.

$5^{\circ}$. La vinculación entre el incremento de la pobreza y "la pobreza del trabajador" es una constatación.

\section{BIBLIOGRAFÍA}

Cáritas Diócesana. VII informe del Observatorio de la realidad social. 2012. 
DE LA GARZA TOLEDO, Enrique. Hacia un concepto ampliado de trabajo: del trabajo clásico al no clásico. [En línea]. México. Libro electrónico: <http:// www.izt.uam.mx/sotraem/Documentos/LibroDebate/LibroDebate.html>. [2010].

DELGADO ACOSTA, Carmen Rosa, CALERO MARTÍN, Carmen Gloria y GARCÍA HERRERA, Luz Marina. Espacios Degradados y Formas de Exclusión Social en Los Puertos Canarios. Boletín de la Asociación de Geógrafos Españoles, 2011, n 56, p. 35 57.

DÍAZ RODRÍGUEZ, María del Carmen, DELGADO ACOSTA, Carmen Rosa, CALERO MARTÍN, Carmen Gloria, GARCÍA HERRERA, Luz Marina, PÉREZ PÉREZ, Mario y MEJÍAS VERA, Miguel Ángel. Ciudad Oscura, Ciudad Luminosa, Santa Cruz de Tenerife (1980-2000). Investigaciones Geográficas, 2002, nº 28, p. 33 51.

DÍAZ RODRÍGUEZ, María del Carmen y DELGADO ACOSTA, Carmen Rosa. La política social en la iniciativa Urban: los proyectos Urban en Tenerife (Canarias). Documents d'Anàlisi Geogràfica, 2008, nº 52, p. 69-90.

ESPLUGA, Josep. LEMKNOW, Louis. BALTIÉRREZ, Josep y KIESELBACH, Thomas. Fundamentos teóricos de la exclusión social y revisión de conceptos relacionados con la exclusión social en la bibliografía española. Desempleo juvenil, exclusión social y salud. Barcelona: Icaria, 2004, p. 75-77.

Ayuntamiento de Santa Cruz de Tenerife. Construir la Ciudad: criterios, objetivos y soluciones generales para la revisión del Plan General de Ordenación Urbana. Santa Cruz de Tenerife: Ayuntamiento de Santa Cruz de Tenerife, 1983.

Fundación Foessa. VI Informe sobre exclusión y desarrollo social en España. Madrid. 2008.

GARCÍA HERRERA, Luz Marina. Santa Cruz de Tenerife, la formación de la ciudad marginal. Santa Cruz de Tenerife: Idea, 2005.

HANSEN, Alvin. Libro II: Definiciones e ideas. Conceptos e ideas. Guía de Keynes. México, D. F.: Fondo de Cultura Económica, 1986, p. 42-63.

HERRERO, Carmen. VILLAR, Antonio y SOLER, Ángel. Desarrollo Humano y Pobreza en España. Valencia: Instituto Valenciano de Investigaciones Económicas (IVIE), 2013.

Instituto Municipal de Atención Social (IMAX). Informe de la atención social 2012. Santa Cruz de Tenerife, 2013.

MARTÍN MARTÍN, Victoriano. La ética y la economía de Adam Smith. El liberalismo económico. Madrid: Síntesis, 2002, p. 267-292. 
MARTÍN RUÍZ, Juan Francisco. La pobreza en África. Las Palmas de Gran Canaria: Anroart, 2009.

MARTÍN RUÍZ, Juan Francisco y DÍAZ RODRÍGUEZ, María del Carmen. Población, empleo y paro en Canarias. Las Palmas de Gran Canaria: Cabildo Insular de Gran Canaria. Departamento de Ediciones, 1983.

MARX, Karl. La ley general de la acumulación capitalista, capítulo XXIII. El Capital. Libro I. Barcelona: Orbis, 1984.

MARX, Karl. Trabajo asalariado y capital; Salario, precio y ganancia. Madrid: Júcar, 1977.

SENENT-JOSA, Joan. Enseñanza y revolución en China. Barcelona: Anagrama, 1977.

SOLIMANO, Andrés. Enfoques alternativos sobre el mercado de trabajo: una evaluación teórica. Revista de Análisis Económico, 1988, vol. 3, n 2, p. 159-186.

TOHARIA, Luis. El mercado de trabajo: Teorías y aplicaciones. Compilación e introducción de Luis Toharia. Madrid: Alianza Editorial, 1983, p. 9-39.

TORRES GUTIÉRREZ, Francisco José y OJEDA RIVERA, Juan Francisco. (2004): La pobreza en Andalucía. Revista SEMATA, Ciencias Sociales y Humanidades, 2004, vol. 16, p. 79-99.

VERCELLI, Alexandro. La depresión y sus remedios. Keynesianismo. Barcelona: Oikos-tau, 1989, p. 54-56.

\section{RECURSOS ELECTRÓNICOS}

La Opinión de Tenerife. Periódico Edición Digital. <http://www.laopinion.es/tenerife/2013/03/03/aluvion-solicitudes-ayudas-capitaldesborda-servicios-sociales/462420.html>. [3 de marzo de 2013].

La Opinión de Tenerife. Periódico Edición Digital <http://www.laopinion.es/tenerife/2013/03/07/tenerife-vecinos-padecenhambruna/463193.html $>$. [7 de marzo de 2013].

El Día. Periódico Edición Digital. <http://eldia.es/2013-03-09/observador/17-hambreazota-ninos-canarios.htm>. [9 de marzo de 2013].

El Día. Periódico Edición Digital. <http://eldia.es/2013-03-03/canarias/2-economiasumergida-valvula-escape-crisis.htm>. [3 de marzo de 2013].

La Opinión de Tenerife. Periódico Edición Digital. <http://www.laopinion.es/economia/2013/03/03/canarias-pierde-43-empleos-diareforma-laboral/462428.html >. [3 de marzo de 2013]. 
El Día. Periódico Edición Digital. <http://eldia.es/2013-03-04/CANARIAS/5-paradosCanarias-cobra-ya-prestaciones-desempleo.htm>. [4 de marzo de 2013].

El Día. Periódico Edición Digital. <http://eldia.es/2013-03-31/vidaycultura/3universitarios-canarios-lideran-cifras-precariedad.htm>. [31 de marzo de 2013].

El Día. Periódico Edición Digital. 〈http://eldia.es/2013-03-18/vidaycultura/1-listaespera-1leva-cientos-canarios-discapacidad>. [18 de marzo de 2013].

Gran Enciclopedia Virtual Islas Canarias (GEVIC). <http://www.gevic.net/info/contenidos/mostrar_contenidos.php?idcat=69\&idcap=261\& idcon=1522>. [25 de junio de 2013].

(C) Copyright Fernando Vicente Muñoz Salazar, 2014.

(C) Copyright GeoGraphos, 2014.

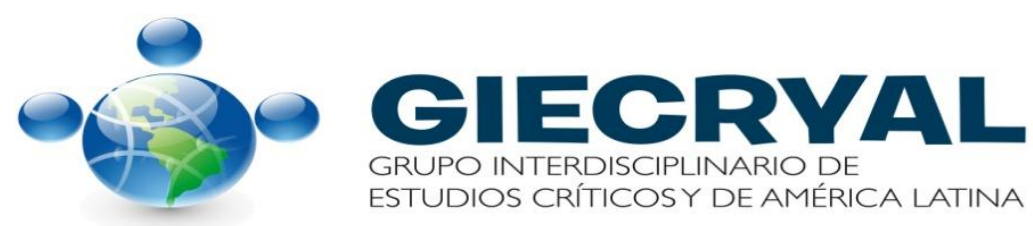

